\title{
¿Southern Ocean Wind Stress in CMIP5 Models: Role of Wind Fluctuations
}

\author{
XIA LIN \\ College of Oceanography, and International Polar Environment Research Laboratory, Hohai University, Nanjing, China
}

XIAOMING ZHAI

Centre for Ocean and Atmospheric Sciences, School of Environmental Sciences, University of East Anglia, Norwich, United Kingdom

ZHAOMIN WANG

College of Oceanography, and International Polar Environment Research Laboratory, Hohai University, Nanjing, China

\author{
DAVID R. MUNDAY
}

British Antarctic Survey, Cambridge, United Kingdom

(Manuscript received 26 June 2019, in final form 26 September 2019)

\begin{abstract}
The Southern Ocean (SO) surface wind stress is a major atmospheric forcing for driving the Antarctic Circumpolar Current and the global overturning circulation. Here the effects of wind fluctuations at different time scales on SO wind stress in 18 models from phase 5 of the Coupled Model Intercomparison Project (CMIP5) are investigated. It is found that including wind fluctuations, especially on time scales associated with synoptic storms, in the stress calculation strongly enhances the mean strength, modulates the seasonal cycle, and significantly amplifies the trends of SO wind stress. In 11 out of the 18 CMIP5 models, the SO wind stress has strengthened significantly over the period of 1960-2005. Among them, the strengthening trend of SO wind stress in one CMIP5 model is due to the increase in the intensity of wind fluctuations, while in all the other 10 models the strengthening trend is due to the increasing strength of the mean westerly wind. These discrepancies in SO wind stress trend in CMIP5 models may explain some of the diverging behaviors in the model-simulated SO circulation. Our results suggest that to reduce the uncertainty in SO responses to wind stress changes in the coupled models, both the mean wind and wind fluctuations need to be better simulated.
\end{abstract}

\section{Introduction}

The Southern Hemisphere (SH) surface westerly wind stress plays an instrumental role in driving the Southern Ocean (SO) circulation and the global meridional overturning circulation (Marshall and Speer 2012; Meredith et al. 2012; Gent 2016), as well as SO temperature changes and carbon uptake (Le Quéré et al. 2007; Gille 2008; Wang et al. 2015; Jones et al. 2016; Wang et al. 2017). Since surface wind stress depends nonlinearly on surface wind velocity (e.g., Large

¿ Denotes content that is immediately available upon publication as open access.

Corresponding authors: Xiaoming Zhai, xiaoming.zhai@uea.ac. uk; Zhaomin Wang, Zhaomin.Wang@hhu.edu.cn et al. 1994), high-frequency wind fluctuations contribute to both the mean strength and low-frequency variability of surface wind stress (Zhai and Wunsch 2013). For example, when wind fluctuations with time scales less than one month are included in the stress calculation, the time-mean wind stress is significantly enhanced, which then leads to an increase in wind power input to the ocean general circulation of over 70\% (Zhai et al. 2012; Wu et al. 2016).

Recently, Lin et al. (2018) investigated the contributions of atmospheric wind fluctuations to the mean, variability, and trend of SO wind stress over the last four decades using reanalysis products. They found that including wind variability at synoptic frequencies (2-8 days) and higher in the stress calculation increases the strength of the mean SO wind stress by as much as almost $40 \%$. However, large discrepancies exist among reanalysis products regarding the role of wind fluctuations 
TABLE 1. Details of CMIP5 models selected in this study. Models resolving the stratosphere well with model tops at or above $1 \mathrm{hPa}$ are defined as high-top models (in boldface). (Expansions of acronyms are available online at http://www.ametsoc.org/PubsAcronymList.)

\begin{tabular}{|c|c|c|c|c|}
\hline Model name & Institute & Horizontal resolution $\left({ }^{\circ}\right.$ lon $\times{ }^{\circ}$ lat $)$ & Vertical levels & Model top (hPa) \\
\hline ACCESS1.0 & CSIRO-BOM (Australia) & $1.875 \times 1.25$ & 38 & 4 \\
\hline ACCESS1.3 & CSIRO-BOM (Australia) & $1.875 \times 1.25$ & 38 & 4 \\
\hline CMCC-CM & CMCC (Italy) & $0.75 \times 0.75$ & 31 & 10 \\
\hline CNRM-CM5 & CNRM-CERFACS (France) & $1.41 \times 1.41$ & 31 & 10 \\
\hline GFDL CM3 & NOAA GFDL (United States) & $2.5 \times 2.0$ & 48 & 0.01 \\
\hline GFDL-ESM2G & NOAA GFDL (United States) & $2.5 \times 2.0$ & 24 & 3 \\
\hline GFDL-ESM2M & NOAA GFDL (United States) & $2.5 \times 2.0$ & 24 & 3 \\
\hline GISS-E2-H & NASA GISS (United States) & $2.5 \times 2.0$ & 40 & 0.1 \\
\hline GISS-E2-R & NASA GISS (United States) & $2.5 \times 2.0$ & 40 & 0.1 \\
\hline HadGEM2-ES & Met Office (United Kingdom) & $1.875 \times 1.25$ & 38 & 4 \\
\hline IPSL-CM5A-LR & IPSL (France) & $3.75 \times 1.875$ & 39 & 0.04 \\
\hline IPSL-CM5A-MR & IPSL (France) & $2.5 \times 1.26$ & 39 & 0.04 \\
\hline MIROC-ESM & MIROC (Japan) & $2.8 \times 2.8$ & 80 & 0.0036 \\
\hline MIROC-ESM-CHEM & MIROC (Japan) & $2.8 \times 2.8$ & 80 & 0.0036 \\
\hline MIROC4h & MIROC (Japan) & $0.56 \times 0.56$ & 56 & 2.3 \\
\hline MIROC5 & MIROC (Japan) & $1.41 \times 1.41$ & 40 & 3 \\
\hline MRI-CGCM3 & MRI (Japan) & $1.125 \times 1.125$ & 48 & 0.01 \\
\hline MRI-ESM1 & MRI (Japan) & $1.125 \times 1.125$ & 48 & 0.01 \\
\hline
\end{tabular}

in determining the strengthening trend of SO wind stress; the strengthening trend in ERA-Interim is due entirely to the increasing strength of the mean westerly wind, while between one-third and one-half of the strengthening trend in NCEP is attributable to the increase in the intensity of wind fluctuations (Lin et al. 2018). These large discrepancies are worrying and may explain some of the diverging behaviors of the model-simulated SO circulation and water mass distribution when forced with different reanalysis products (e.g., Zika et al. 2013a,b; Langlais et al. 2015). As highlighted recently by Munday and Zhai (2017), the sensitivity of SO circulation to wind stress changes depends strongly on how these stress changes are brought about (i.e., whether via changes of the mean wind or changes of wind variability). In their model experiments, when the increase in SO wind stress is made by increasing the intensity of wind variability, vertical mixing and water mass transformation processes are enhanced in the mixed layer, which results in a much greater sensitivity of the SO meridional overturning circulation to the increased wind stress. Therefore, to understand how the climate system may respond to the observed and predicted increase in SO wind stress, it is important to first understand how this increase in wind stress is brought about.

Models from phase 5 of the Coupled Model Intercomparison Project (CMIP5) are widely used to simulate historical and predict future changes of the strength and position of the SO surface westerly winds (Ceppi et al. 2012; Swart and Fyfe 2012; Wilcox et al. 2012; Barnes and Polvani 2013; Bracegirdle et al. 2013; Lee et al. 2013; Swart et al. 2015; Simpson and Polvani 2016).
However, whether these SO wind stress changes simulated and predicted in CMIP5 models are brought about by changes of the mean westerly winds, changes of wind variability, or both is unknown. The general role of wind fluctuations in determining the strength of $\mathrm{SO}$ wind stress in CMIP5 models is also unclear. The answers to these questions may prove useful for understanding the large spread in the model-simulated SO circulation and water masses under different scenarios (Wang et al. 2011; Meijers et al. 2012; Downes and Hogg 2013; Sallée et al. 2013a,b; Wang 2013; Meijers 2014; Russell et al. 2018). In this study, we investigate for the first time the effects of wind fluctuations on the mean, seasonal cycle, and trend of SO wind stress in CMIP5 models and compare them with results from two reanalysis products.

The paper is organized as follows. The CMIP5 models and reanalysis products chosen for this study are described in section 2, followed by an explanation of the analysis method used in section 3 . In section 4 , results of the effects of wind fluctuations at different time scales on the mean, seasonal cycle, and trend of the SO wind stresses in CMIP5 models are presented, discussed, and compared with those from the reanalysis products. Finally, conclusions and discussion of implications of our results are provided in section 5 .

\section{CMIP5 models and reanalysis products}

The CMIP5 models used in this study are listed in Table 1 together with model details such as model resolution and whether they are stratosphere-resolving. CMIP5 models provide monthly mean surface wind 
stresses and 18 of them at the time of this study provide 6-hourly $10-\mathrm{m}$ wind velocities. To quantify the contributions from wind fluctuations at different time scales to the SO wind stress, we recalculate wind stresses with wind fluctuations from these 18 models with certain time scales included or excluded by using an approximate formulation of the dependence on 10-m wind speed. Only model output from historical runs (1960-2005) is assessed, since for future projection simulations (representative concentration pathways RCP4.5 and RCP8.5), 6-hourly wind velocities are only provided for two 20 -yr periods of 2026-46 and 2081-2100, which are not long enough for estimating the trend significance.

Results from the CMIP5 models are compared with two widely used atmospheric reanalysis products: the Japanese 55-year Reanalysis (JRA-55; Kobayashi et al. 2015) and the ECMWF interim reanalysis (ERA-Interim; Dee et al. 2011). The horizontal resolutions of JRA-55 and ERA-Interim are T319 $(\sim 63 \mathrm{~km})$ and T255 $(\sim 80 \mathrm{~km})$, respectively. The strength of the $\mathrm{SH}$ westerly jet from reanalysis data suffers large spurious trends prior to 1979 but this situation is much improved after 1979, thanks to the assimilation of Television Infrared Observation Satellite (TIROS) Operational Vertical Sounder (TOVS) data into the reanalysis model (Hines et al. 2000; Kistler et al. 2001; Marshall 2003). In addition, the ERA-Interim winds are only provided from 1979 . Therefore, we choose to compare CMIP5 model outputs from historical runs and the two reanalysis products over their overlapping period of 1979-2005. Note that the differences between the mean wind stresses in CMIP5 models over the period of 1979-2005 and those of 1960-2005 are generally very small (not shown). However, neither the trends of SO wind stress in CMIP5 models nor those in the two reanalysis products are significant over the period of 19792005. For this reason, the trends of SO wind stress in CMIP5 models are calculated over the longer period of 1960-2005 and are not compared with those from reanalysis products whose trends are known to be spurious prior to 1979 .

\section{Methods}

Based on Monin-Obukhov similarity theory (MOST; Garratt 1994), bulk surface flux parameterizations are used to estimate air-sea fluxes in CMIP5 models (Knutti et al. 2013; Ma et al. 2015; Simpson et al. 2018) and bulk algorithms used to calculate surface momentum and heat flux exchanges were provided in Fairall et al. (2003). Following Fairall et al. (2003), the zonal surface wind stress in our study is calculated based on the bulk formula $\tau_{x}=\rho_{a} c_{d}\left|U_{10}\right| u_{10}$, where $\tau_{x}$ is the surface zonal wind stress, $\left|U_{10}\right|$ is the $10-\mathrm{m}$ wind speed, $u_{10}$ is the $10-\mathrm{m}$ zonal wind velocity, $\rho_{a}$ is air density at the sea surface (set to a constant of $1.223 \mathrm{~kg} \mathrm{~m}^{-3}$ ), and $c_{d}$ is the variable drag coefficient. Here $c_{d}$ is set to the drag coefficient in neutrally stable conditions from empirical functions $c_{d}^{1 / 2}=c_{d n}^{1 / 2}=\kappa / \ln \left(z / z_{0}\right)$ with the MOST stability parameter $\zeta=0$, where $\kappa$ is von Kármán's constant, $z$ is the height of wind measurement, and $z_{0}$ is the roughness length for momentum. Following Smith (1988), the roughness length is set to $z_{0}=\left(\alpha u_{*}^{2} / g\right)+\left(0.11 \nu / u_{*}\right)$, where $\alpha$ is the Charnock parameter, $u_{*}$ is the surface frictional velocity, and gravitational acceleration $g$ and kinematic viscosity $\nu$ are constants. The Charnock parameter $\alpha$ varies with wind velocity and the surface frictional velocity is set to $u_{*}=\kappa \sqrt{\left|U_{10}\right|^{2}+u_{g}^{2}} / \ln \left(z / z_{0}\right)$ with a gustiness part $u_{g}$ set to zero in neutrally stable conditions (Beljaars 1995; Fairall et al. 2003). As shown in Fig. 1, the time-mean wind stresses calculated from 6hourly winds of the 18 CMIP5 models provide a reasonably close match to those averaged from model output monthly mean stresses. Differences in mean wind stress can be attributed to neglecting atmosphere stability, waves, and surface ocean currents, as well as different Charnock parameter and gustiness used in our calculation of surface drag coefficient.

The methods used in this study to evaluate the effects of wind fluctuations at different time scales on the SO wind stress are similar to those in Lin et al. (2018) but with some modifications. It is worth pointing out that owing to the modulus function in the bulk formula the contribution of wind fluctuations to the mean stress depends strongly on the presence of the mean winds (Zhai 2013). For example, if the mean winds are ignored in the stress calculation, the mean stress, to first-order approximation, vanishes regardless of the strength of wind fluctuations. Here we follow Zhai (2013) and Lin et al. (2018) and quantify the effects of including wind fluctuations at different time scales on the mean stress by including or excluding these wind fluctuations in the stress calculation.

Different from Lin et al. (2018), we apply Lanczos low-pass filter with 100 weights, rather than the simple running mean, to the time series of 6-hourly CMIP5 and reanalysis wind velocities at every model grid point to filter out wind fluctuations that last less than 2 and 8 days. We have also tested the Butterworth filter and results are almost identical to those using the Lanczos filter. Wind fluctuations on time scales of 2-8 days are calculated by taking the difference between the 2 - and 8 -day low-pass-filtered wind fields. We then obtain the 2-8-day-filtered winds by removing wind fluctuations on time scales of 2-8 days from the original 6hourly wind field (Table 2). Finally, we recalculate the zonal wind stresses $\tau_{>2 \mathrm{~d}}, \tau_{>8 \mathrm{~d}}, \tau_{<2 \mathrm{~d} \&>8 \mathrm{~d}}$, and $\tau_{>\mathrm{yr}}$ using 

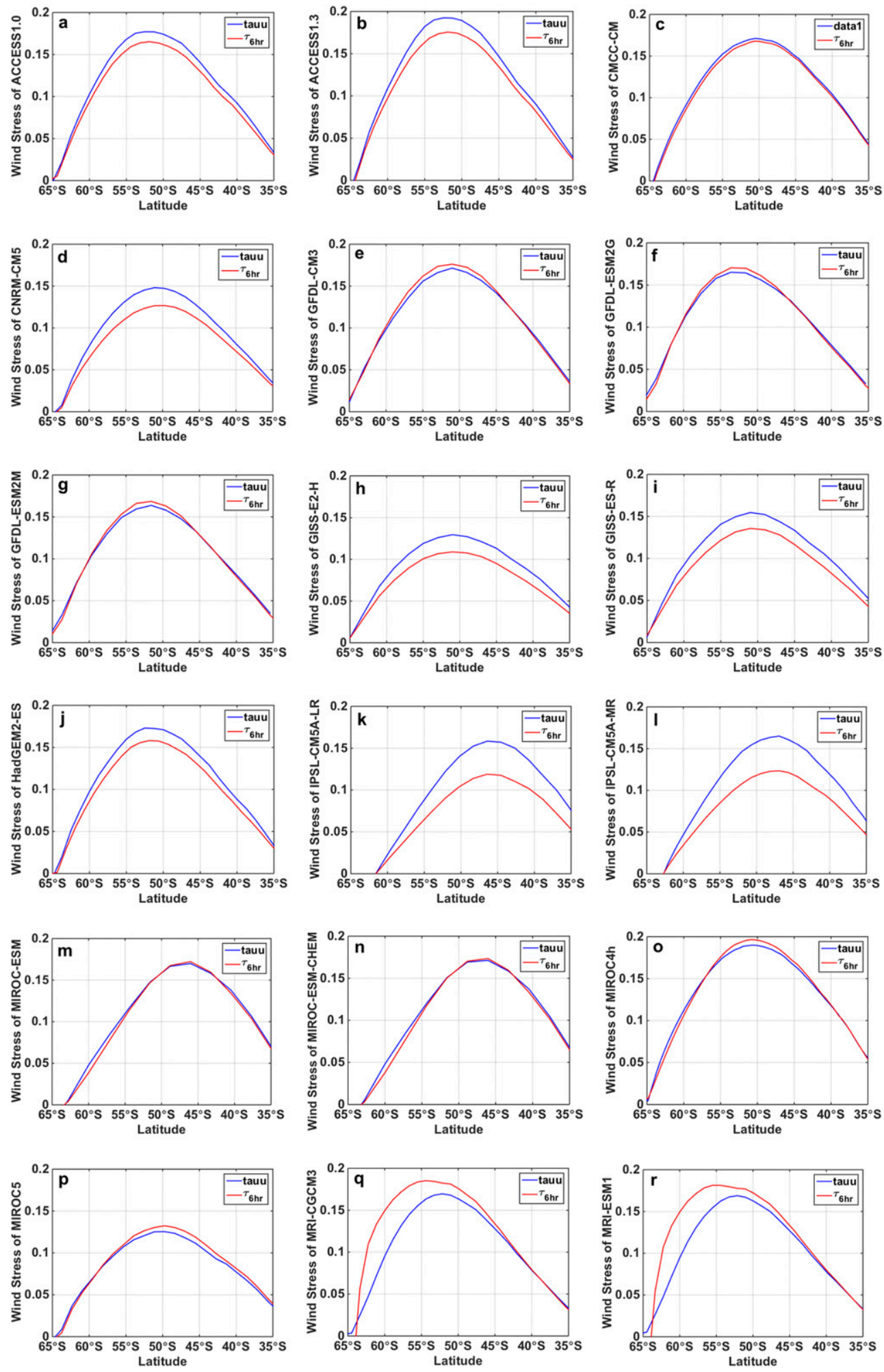

FIG. 1. The 1979-2005 time-mean and zonal-mean zonal wind stresses from the 18 CMIP5 models $\left(\mathrm{N} \mathrm{m}^{-2}\right)$. The blue curve is calculated using monthly mean wind stress data from the model output; the red curve is calculated using $\tau_{>6 \mathrm{hr}}$ that is derived from the bulk formula and 6-hourly winds. 
TABLE 2. List of variables and formulas used in this study. The variables are defined similarly to Lin et al. (2018), so the following text is derived from there with some minor changes. The Lanczos low-pass filter is applied to the time series of 6-hourly wind velocities. Overbars $\ldots_{\mathrm{yr}}, \ldots^{2 \mathrm{~d}}, \ldots^{8 \mathrm{~d}}$, and $\ldots^{2-8 \mathrm{~d}}$ represent annual-mean, 2-day low-pass-filtered, 8-day low-pass-filtered, and 2-8-day-filtered winds, respectively, and the superscript " $6 \mathrm{hr}$ " indicates 6-hourly winds. Wind fluctuations on time scales of 2-8 days are removed from the 6-hourly wind fields to obtain the 2-8-day-filtered winds, i.e., ${\overline{u_{10}}}^{2-8 \mathrm{~d}}=u_{10}^{6 \mathrm{hr}}-\left({\overline{u_{10}}}^{2 \mathrm{~d}}-{\overline{u_{10}}}^{8 \mathrm{~d}}\right)$ and ${\overline{v_{10}}}^{2-8 \mathrm{~d}}=v_{10}^{6 \mathrm{hr}}-\left({\overline{v_{10}}}^{2 \mathrm{~d}}-{\overline{v_{10}}}^{8 \mathrm{~d}}\right)$. The 2-8-day-filtered wind speed is then calculated from $\left|{\overline{U_{10}}}^{2-8 \mathrm{~d}}\right|=\sqrt{\left({\overline{u_{10}}}^{2-8 \mathrm{~d}}\right)^{2}+\left({\overline{v_{10}}}^{2-8 \mathrm{~d}}\right)^{2}}$.

\begin{tabular}{|c|c|c|}
\hline Variable & Definition & Formula \\
\hline$\tau_{>6 \mathrm{hr}}$ & $\begin{array}{l}\text { Zonal wind stress calculated from 6-hourly } \\
\text { winds }\end{array}$ & $\overline{\rho_{a} c_{d}\left|U_{10}^{6 \mathrm{hr}}\right| u_{10}^{6 \mathrm{hh}}{ }^{\mathrm{yr}}}$ \\
\hline$\tau_{>2 \mathrm{~d}}$ & $\begin{array}{l}\text { Zonal wind stress calculated from 2-day-filtered } \\
\text { winds }\end{array}$ & 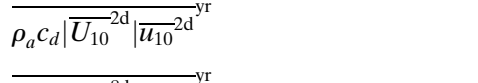 \\
\hline$\tau_{>8 \mathrm{~d}}$ & $\begin{array}{l}\text { Zonal wind stress calculated from 8-day-filtered } \\
\text { winds }\end{array}$ & 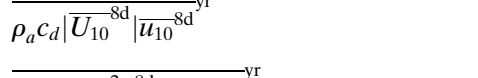 \\
\hline$\tau<2 \mathrm{~d} \&>8 \mathrm{~d}$ & $\begin{array}{l}\text { Zonal wind stress calculated from 2-8-day-filtered } \\
\text { winds }\end{array}$ & 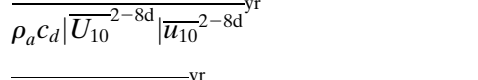 \\
\hline$\tau_{>\mathrm{yr}}$ & $\begin{array}{l}\text { Zonal wind stress calculated from annual-mean } \\
\text { winds }\end{array}$ & $\bar{\rho}_{a} c_{d}\left|{\overline{U_{10}}}^{\mathrm{yr}}\right| \overline{u_{10}}{ }^{\mathrm{yr}}$ \\
\hline $\mathrm{MKE}_{<\mathrm{yr}}$ & $\begin{array}{l}\text { Kinetic energy calculated from annual-mean } \\
\text { winds }\end{array}$ & {$\left[\overline{\left({\overline{u_{10}}}^{\mathrm{yr}}\right)^{2}+\left({\overline{v_{10}}}^{\mathrm{yr}}\right)^{2}}{ }^{\mathrm{yr}}\right] / 2$} \\
\hline $\mathrm{EKE}_{<\mathrm{yr}}$ & $\begin{array}{l}\text { Kinetic energy calculated from wind } \\
\text { fluctuations on time scales of } 6 \mathrm{~h}-1 \text { year }\end{array}$ & $\left.\left(u_{10}^{6 \mathrm{hr}}-{\overline{u_{10}}}^{\mathrm{yr}}\right)^{2}+\left(v_{10}^{6 \mathrm{hr}}-{\overline{v_{10}}}^{\mathrm{yr}}\right)^{2}{ }^{\mathrm{yr}}\right] / 2$ \\
\hline $\mathrm{EKE}_{<2 \mathrm{~d}}$ & $\begin{array}{l}\text { Kinetic energy calculated from wind } \\
\text { fluctuations on time scales of } 6 \mathrm{~h}-2 \text { days } \\
\text { alone }\end{array}$ & 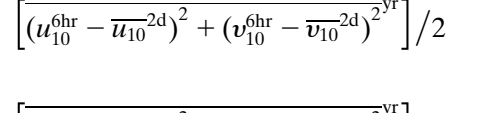 \\
\hline $\mathrm{EKE}_{<8 \mathrm{~d}}$ & $\begin{array}{l}\text { Kinetic energy calculated from wind fluctuations on } \\
\text { time scales of } 6 \mathrm{~h}-8 \text { days } \\
\text { alone }\end{array}$ & 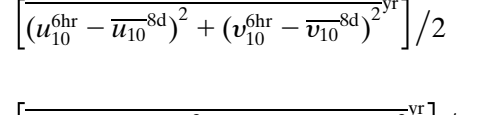 \\
\hline $\mathrm{EKE}_{2-8 \mathrm{~d}}$ & $\begin{array}{l}\text { Kinetic energy calculated from wind } \\
\text { fluctuations on time scales of } 2-8 \text { days } \\
\text { alone }\end{array}$ & $\left.\left.\left[{\overline{\left(\bar{u}_{10}\right.}}^{2 \mathrm{~d}}-{\overline{u_{10}}}^{8 \mathrm{~d}}\right)^{2}+\left({\overline{v_{10}}}^{2 \mathrm{~d}}-{\overline{v_{10}}}^{8 \mathrm{~d}}\right)^{2}\right)^{13}\right] / 2$ \\
\hline
\end{tabular}

2-day-filtered, 8-day-filtered, 2-8-day-filtered, and annualmean winds, respectively (Table 2 ), and compare them with the zonal wind stress $\tau_{>6 \mathrm{hr}}$ calculated from the original 6-hourly winds $\left(\tau_{>6 \mathrm{hr}}-\tau_{>2 \mathrm{~d}}, \tau_{>6 \mathrm{hr}}-\tau_{>8 \mathrm{~d}}\right.$, $\left.\tau_{>6 \mathrm{hr}}-\tau_{<2 \mathrm{~d} \&>8 \mathrm{~d}}, \tau_{>6 \mathrm{hr}}-\tau_{>\mathrm{yr}}\right)$ to quantify the influences of including wind fluctuations on time scales of less than 2 days, less than 8 days, 2-8 days, and less than a year in the stress calculation. For example, since wind fluctuations of $6 \mathrm{~h}-2$ days are excluded in the calculation of $\tau_{>2 \mathrm{~d}}$, the difference between $\tau_{>6 \mathrm{hr}}$ and $\tau_{>2 \mathrm{~d}}$ can be used to quantify the effect of including wind fluctuations of $6 \mathrm{~h}-2$ days on the mean stress. Threshold time scales of 2 and 8 days are chosen because atmospheric variability on time scales of 2-8 days is generally thought to be associated with synoptic weather systems and baroclinic storm activities (e.g., Trenberth 1991; Yin 2005).

In addition, we also calculate and compare mean kinetic energy (MKE) and eddy kinetic energy (EKE) associated with the SO 10-m winds in CMIP5 models and reanalysis products. MKE in each year $\left(\mathrm{MKE}_{<\mathrm{yr}}\right)$ at every grid point is calculated from the annual-mean wind field, and EKE at every grid point is calculated from wind fluctuations on time scales of $6 \mathrm{~h}-2$ days
$\left(\mathrm{EKE}_{<2 \mathrm{~d}}\right), 2-8$ days $\left(\mathrm{EKE}_{2-8 \mathrm{~d}}\right), 6 \mathrm{~h}-8$ days $\left(\mathrm{EKE}_{<8 \mathrm{~d}}\right)$, and $6 \mathrm{~h}-1$ year $\left(\mathrm{EKE}_{<\mathrm{yr}}\right)$, respectively (see Table 2 for the formulas). For example, $\mathrm{EKE}_{<2 \mathrm{~d}}$ is calculated using the difference between the 6-hourly and 2-day low-passfiltered wind fields. As such, $\mathrm{EKE}_{<2 \mathrm{~d}}$ represents kinetic energy associated with wind fluctuations on time scales of $6 \mathrm{~h}-2$ days alone and does not include the nonlinear cross term between fluctuations of $6 \mathrm{~h}-2$ days and those of 2 days -1 year.

\section{Results}

\section{a. Mean state}

\section{1) MeAn Wind And STRESS}

Figure 2 shows the 1979-2005 time-mean and zonalmean zonal wind velocities (dashed lines) and zonal wind stresses (solid lines) in the SO from the 18 CMIP5 models and two reanalysis data. There are considerable differences among them. The peak zonal wind velocities vary from $5.3 \mathrm{~m} \mathrm{~s}^{-1}$ in GISS-E2-H to $7.3 \mathrm{~m} \mathrm{~s}^{-1}$ in MIROC4h and peak values of $\tau_{>6 \mathrm{hr}}$ (red lines) vary from less than $0.11 \mathrm{~N} \mathrm{~m}^{-2}$ in GISS-E2-H to over $0.19 \mathrm{~N} \mathrm{~m}^{-2}$ in 

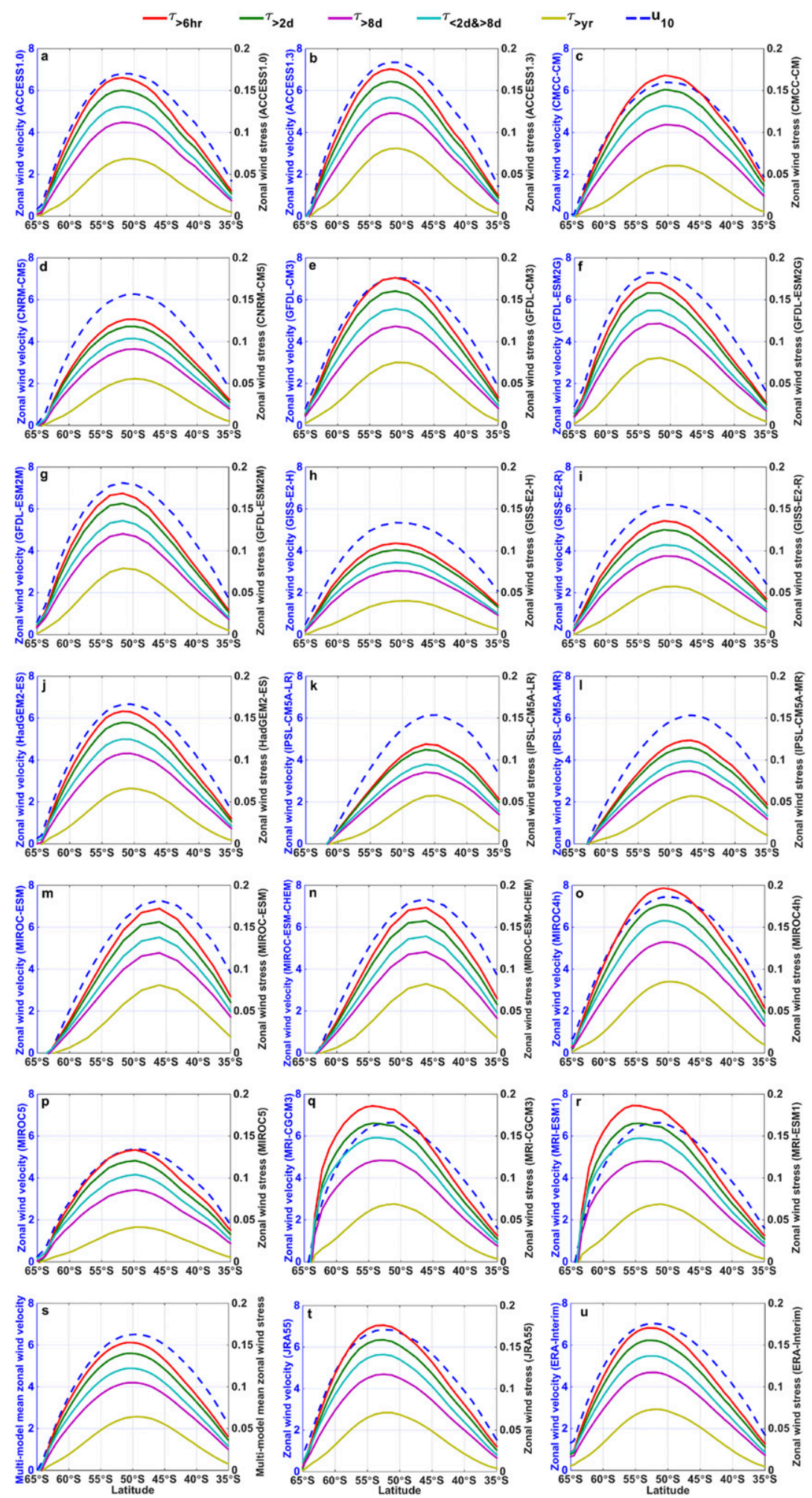

FIG. 2. The 1979-2005 time-mean and zonal-mean zonal wind velocities (dashed; $\mathrm{m} \mathrm{s}^{-1}$ ) and zonal wind stresses (solid; $\mathrm{N} \mathrm{m}^{-2}$ ) from (a)-(r) the 18 CMIP5 models, (s) their multimodel mean, (t) JRA-55, and (u) ERA-Interim. Mean $\tau_{>6 \mathrm{hr}}, \tau_{>2 \mathrm{~d}}, \tau_{<2 \mathrm{~d} \&>8 \mathrm{~d}}, \tau_{>8 \mathrm{~d}}$, and $\tau_{>\mathrm{yr}}$ are calculated from the 6-hourly, 2-day-filtered, 8-day-filtered, 2-8-day-filtered, and annual-mean winds, respectively (see Table 2). 

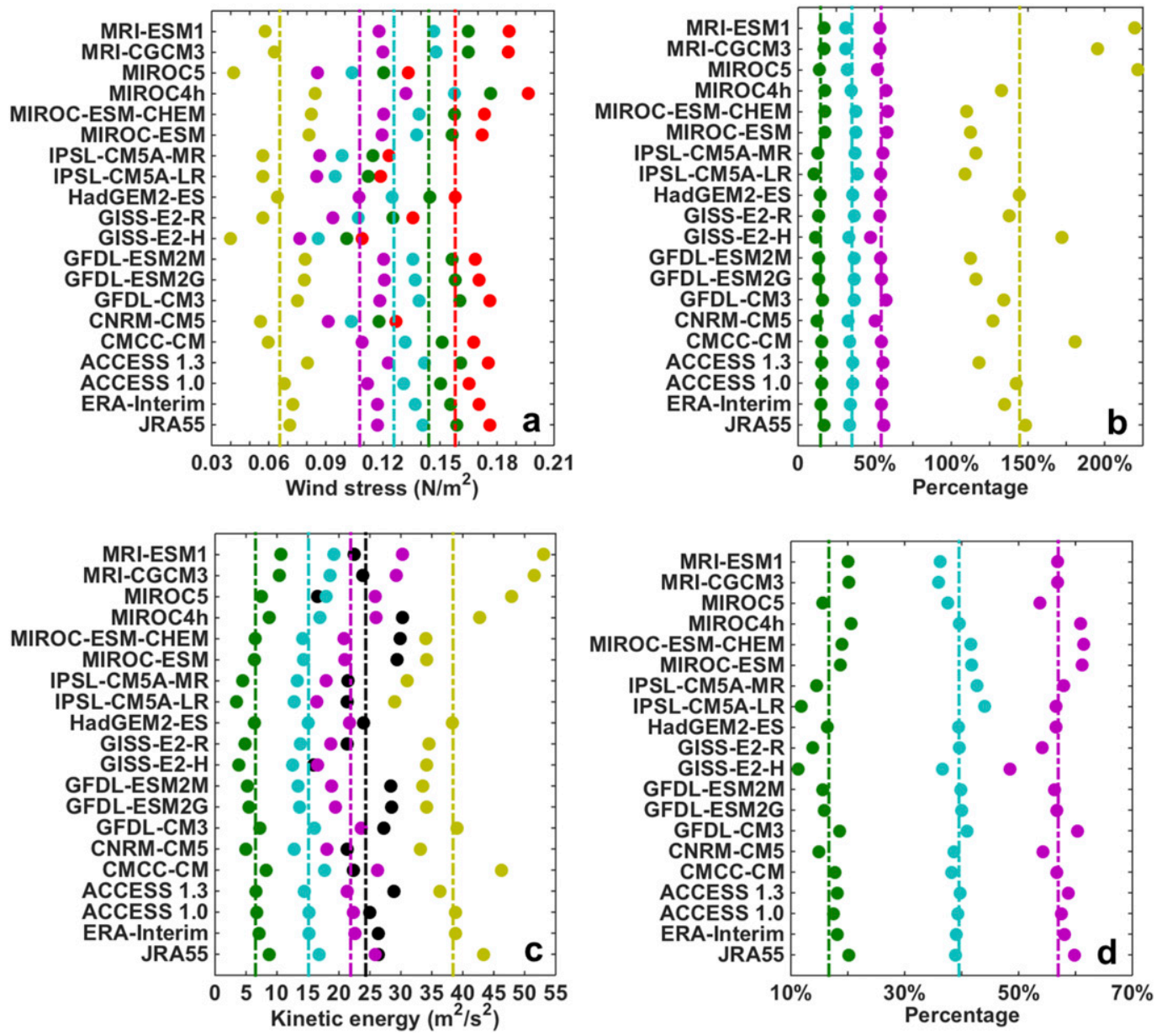

FIG. 3. The peak values of 1979-2005 time-mean and zonal-mean (a) $\tau_{>6 \mathrm{hr}}\left(\right.$ red), $\tau_{>2 \mathrm{~d}}$ (green), $\tau_{<2 \mathrm{~d} \&>8 \mathrm{~d}}$ (cyan), $\tau_{>8 \mathrm{~d}}$ (purple), and $\tau_{>\text {yr }}$ (yellow-green) shown in Fig. 2 over the Southern Ocean $\left(35^{\circ}-65^{\circ} \mathrm{S}\right)$ from 18 CMIP5 models and 2 reanalysis products. (b) Percentage increases in the peak value of the zonal-mean and time-mean wind stress when including in the stress calculation wind fluctuations on time scales less than a year $\left[\left(\tau_{>6 \mathrm{hr}}-\tau_{>\mathrm{yr}}\right) / \tau_{>\mathrm{yr}}\right.$; yellowgreen], and contributions from wind fluctuations of $6 \mathrm{~h}-2$ days $\left[\left(\tau_{>6 \mathrm{hr}}-\tau_{>2 \mathrm{~d}}\right) /\left(\tau_{>6 \mathrm{hr}}-\tau_{>\mathrm{yr}}\right)\right.$; green $]$, $2-8$ days $\left[\left(\tau_{>6 \mathrm{hr}}-\tau_{<2 \&>8 \mathrm{~d}}\right) /\left(\tau_{>6 \mathrm{hr}}-\tau_{>\mathrm{yr}}\right)\right.$; cyan], and $6 \mathrm{~h}-8$ days $\left[\left(\tau_{>6 \mathrm{hr}}-\tau_{>8 \mathrm{~d}}\right) /\left(\tau_{>6 \mathrm{hr}}-\tau_{>\mathrm{yr}}\right)\right.$; purple]. (c) As in (a), but for $M_{K E_{<y r}}$ (black), $\mathrm{EKE}_{<2 \mathrm{~d}}$ (green), $\mathrm{EKE}_{2-8 \mathrm{~d}}(\mathrm{cyan}), \mathrm{EKE}_{<8 \mathrm{~d}}$ (purple), and $\mathrm{EKE}_{<\mathrm{yr}}$ (yellow-green). (d) The ratios of $\mathrm{EKE}_{<2 \mathrm{~d}} / \mathrm{EKE}_{<\mathrm{yr}}$ (green), $\mathrm{EKE}_{2-8 \mathrm{~d}} / \mathrm{EKE}_{<\mathrm{yr}}(\mathrm{cyan})$, and $\mathrm{EKE}_{<8 \mathrm{~d}} / \mathrm{EKE}_{<\mathrm{yr}}$ (purple). The dash-dotted lines mark the corresponding MMM values.

MIROC4h (see also red dots in Fig. 3a). The multimodel mean (MMM) zonal wind velocity and wind stress are smaller than those from two reanalysis products (Figs. 2s-u and 3a). A large spread is shown in the latitudes of peak zonal wind velocities and peak zonal wind stresses, ranging from $\sim 45^{\circ}$ to $\sim 55^{\circ} \mathrm{S}$ in CMIP5 models. On the other hand, the latitudes of peak zonal wind stress and peak zonal wind velocity in the same model are close to each other, except in MRI-CGCM3 and MRI-ESM1. These results are consistent with the findings of previous studies (e.g., Bracegirdle et al. 2013; Lee et al. 2013).

There is also an equatorward bias of about $2^{\circ}$ in the latitudes of maximum MMM zonal wind velocity and $\tau_{>6 \mathrm{hr}}$, compared to those in JRA-55 and ERA-Interim (Figs. 2s-u). This equatorward bias in the position of climatological zonal-mean SO winds exists in most CMIP5 models (Swart and Fyfe 2012; Wilcox et al. 2012; Bracegirdle et al. 2013; Russell et al. 2018). Ceppi et al. (2012) have argued that this equatorward bias is due to surface temperature gradient anomalies induced by midlatitude shortwave cloud forcing bias. High-top models with model tops at or above $1 \mathrm{hPa}$ are marked in boldface in Table 1. On average the mean positions of peak zonal winds in high-top models and low-top models are $49^{\circ}$ and $51^{\circ} \mathrm{S}$, respectively. The larger equatorward bias found in high-top models can be related to the different upper meridional temperature gradients in 

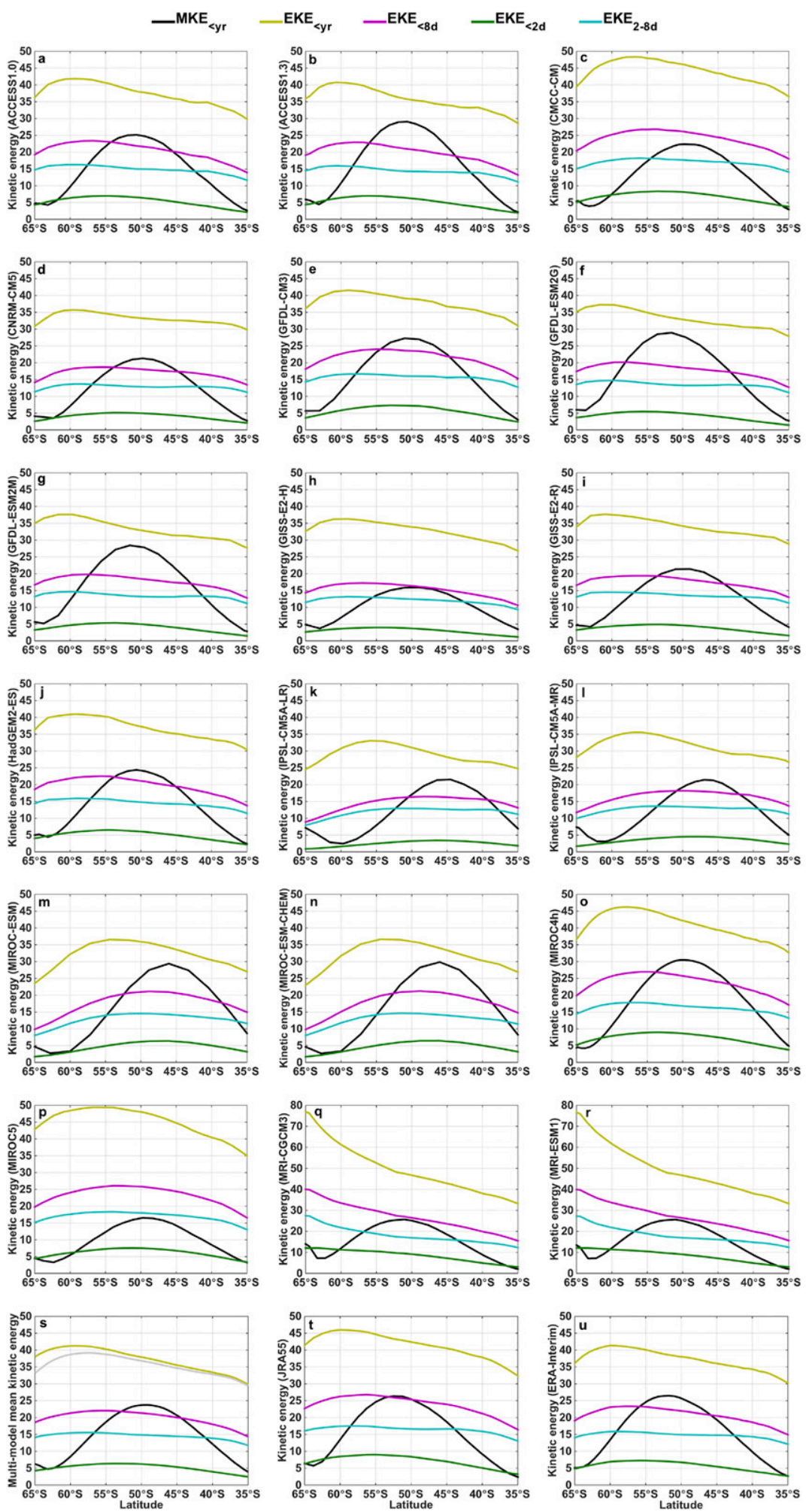

FIG. 4. The 1979-2005 time-mean and zonal-mean mean kinetic energy $\left(\mathrm{m}^{2} \mathrm{~s}^{-2}\right)$ and eddy kinetic energy $\left(\mathrm{m}^{2} \mathrm{~s}^{-2}\right)$ from (a)-(r) the 18 CMIP5 models, (s) their multimodel mean, (t) JRA-55, and (u) ERA-Interim. $\mathrm{MKE}_{<\mathrm{yr}}$ (black) at every grid point is calculated from the annual-mean winds in each year, and $\mathrm{EKE}_{<2 \mathrm{~d}}$ (green), $\mathrm{EKE}_{2-8 \mathrm{~d}}$ (cyan), $\mathrm{EKE}_{<8 \mathrm{~d}}$ (purple), and $\mathrm{EKE}_{<\mathrm{yr}}$ (yellow-green) at every grid point are calculated from wind 
high-top and low-top models (Wilcox et al. 2012; Bracegirdle et al. 2013).

\section{2) CONTRIBUTIONS FROM WIND FLUCTUATIONS TO MEAN STRESS}

In all 18 CMIP5 models (Figs. 2a-r), the magnitude of $\tau_{>6 \mathrm{hr}}$ (red lines) is significantly greater than that of $\tau_{>\mathrm{yr}}$ (yellow-green lines), confirming that wind fluctuations are a large contribution to the mean zonal wind stress in the SO (Zhai 2013). This is to be expected given the large wind variability in this storm-track region and the nonlinear dependence of surface wind stress on surface wind velocity. The effect of including wind fluctuations of $6 \mathrm{~h}-8$ days (red vs purple lines) in the stress calculation is found to be comparable to that of including fluctuations of 8 days- 1 year (purple vs yellow-green lines) in all 18 models. This result implies that wind fluctuations on a relatively narrow time scale range of 6 h-8 days make a disproportionately large contribution to the magnitude of the mean stress. Furthermore, the effect of including wind fluctuations of $2-8$ days on the mean stress (cyan to red lines) is greater than that from including wind fluctuations of $6 \mathrm{~h}-2$ days (green to red lines in Fig. 2). These conclusions from the CMIP5 models are consistent with those from the reanalysis data (Figs. 2s-u).

Figure 3a shows a quantitative comparison of the peak values of the 1979-2005 time-mean and zonal-mean $\tau_{>6 \mathrm{hr}}\left(\right.$ red), $\tau_{>2 \mathrm{~d}}$ (green), $\tau_{<2 \mathrm{~d} \&>8 \mathrm{~d}}\left(\right.$ cyan), $\tau_{>8 \mathrm{~d}}$ (purple), and $\tau_{>\text {yr }}$ (yellow-green) from the 18 CMIP5 models and two reanalysis products. Although the spread among the CMIP5 models is large for wind stresses calculated from 6-hourly and four filtered 10-m wind fields, the overall effect of including wind fluctuations at different time scales on the peak mean wind stress is qualitatively similar. Focusing on the comparison between the MMM and reanalysis products, the peak values of $\tau_{>\mathrm{yr}}$ (yellow-green) are 0.066, 0.071, and $0.073 \mathrm{~N} \mathrm{~m}^{-2}$ for the MMM (dashed line), JRA-55, and ERA-Interim, respectively, and those of $\tau_{>6 \mathrm{hr}}$ (red) are $0.158,0.176$, and $0.170 \mathrm{~N} \mathrm{~m}^{-2}$. The peak value of MMM $\tau_{>\mathrm{yr}}$ is less than those in the two reanalysis products due to weaker mean winds in CMIP5 models (Figs. 2s-u), while the smaller peak value of MMM $\tau_{>6 \mathrm{hr}}$ is due to both weaker mean winds and weaker wind fluctuations (Fig. 3c). Stronger wind fluctuations in JRA-55 lead to a greater strengthening effect on the mean stress via the nonlinear stress law [see derivation in Zhai (2013)], which leads to a larger $\tau_{>6 \mathrm{hr}}$ in JRA-55 than in ERAInterim (Figs. 3a,c).

Including wind fluctuations on time scales less than one year in the stress calculation is found to increase the magnitude of peak zonal-mean zonal wind stress in the MMM, JRA-55, and ERA-Interim by about $145 \%$, $148 \%$, and $135 \%$, respectively (yellow-green line and dots in Fig. 3b), with over $54 \%$ of the increase in the MMM and both reanalysis products being contributed by wind fluctuations on time scales of $6 \mathrm{~h}-8$ days (purple line and dots). Including wind fluctuations on time scales of $6 \mathrm{~h}-2$ days and 2-8 days in the stress calculation act to increase the peak zonal-mean and time-mean wind stress in both MMM and two reanalysis products by around $15 \%$ and $35 \%$, respectively (green and cyan lines and dots in Fig. 3b). Further dividing the CMIP5 models into different groups according to model resolution and whether stratosphere-resolving reveals no relationship between the effects of wind fluctuations on the mean stress and these model parameters/configurations (not shown).

\section{3) KinetiC ENERGY}

The MKE and EKE are related to the large-scale mean wind field and wind fluctuations on much smaller scales, respectively. It is instructive to examine MKE and EKE in the CMIP5 models to understand the effect of mean wind and wind fluctuations at different time scales on the mean wind stress. Figure 4 shows the 19792005 time-mean and zonal-mean MKE and EKE, which are obtained by applying time average and zonal average to MKE and EKE calculated at every grid point. A few common features, consistent with results from the reanalysis products, emerge in all 18 CMIP5 models. First, the zonal-mean $\mathrm{EKE}_{<\mathrm{yr}}$ is greater than the zonal-mean $\mathrm{MKE}_{<\mathrm{yr}}$ over the entire SO latitude range $\left(35^{\circ}-65^{\circ} \mathrm{S}\right)$. Second, the meridional distribution of the zonal-mean $\mathrm{EKE}_{<2 \mathrm{~d}}, \mathrm{EKE}_{2-8 \mathrm{~d}}, \mathrm{EKE}_{<8 \mathrm{~d}}$, and $\mathrm{EKE}_{<\mathrm{yr}}$ is much broader and more uniform compared to $\mathrm{MKE}_{<\mathrm{yr}}$. The zonal-mean $\mathrm{EKE}_{<\mathrm{yr}}$ typically increases gradually southward to roughly $55^{\circ}-60^{\circ} \mathrm{S}$ before it drops more sharply poleward of that latitude band, except for MRICGCM3 and MRI-ESM1 where the zonal-mean EKE $\mathrm{C}_{<\mathrm{yr}}$ increases monotonically southward and reaches values as high as $80 \mathrm{~m}^{2} \mathrm{~s}^{-2}$ (yellow-green lines in Figs. $4 \mathrm{q}$ and $4 \mathrm{r}$ ).

fluctuations on time scales of $6 \mathrm{~h}-2$ days, 2-8 days, $6 \mathrm{~h}-8$ days, and $6 \mathrm{~h}-1$ year, respectively (see Table 2). The maximum values of the vertical axis in MRI-CGCM3 in (q) and MRIESM1 in (r) are adjusted to $80 \mathrm{~m}^{2} \mathrm{~s}^{-2}$. The gray line in (s) is the MMM without MRICGCM3 and MRI-ESM1. 
As a consequence of this monotonic increase of $\mathrm{EKE}_{<\mathrm{yr}}$ with latitude, the distribution of $\tau_{>6 \mathrm{hr}}$ in these two models is skewed heavily southward (red lines in Figs. 2q and 2r). Further analysis shows that excluding results from MRICGCM3 and MRI-ESM1 leads to a noticeable decrease in the magnitude of the MMM EKE $\mathrm{Cyr}_{<\mathrm{r}}$, particularly south of $55^{\circ} \mathrm{S}$ (gray vs yellow-green in Fig. 4s). However, it is worth pointing out that the time and zonal averages of model output monthly mean wind stress from MRI-CGCM3 and MRI-ESM1 show no such large southward skewness (Figs. 1q,r). Third, $\mathrm{EKE}_{2-8 \mathrm{~d}}$ is larger than $\mathrm{EKE}_{<2 \mathrm{~d}}$ in the SO (cyan vs green lines in Fig. 4), which explains why the effect of including wind fluctuations on time scales of $2-8$ days on the mean stress is greater than that of including wind fluctuations of $6 \mathrm{~h}-$ 2 days.

The peak values of the $M M M E E_{<2 d}, E K E_{2-8 d}$, $\mathrm{EKE}_{<8 \mathrm{~d}}$, and $\mathrm{EKE}_{<\mathrm{yr}}$ are close to values from ERAInterim although slightly smaller than those from JRA55 (Fig. 3c). This is consistent with the results shown in Harvey et al. (2012), who demonstrated that the MMM storm tracks in CMIP5 models resemble the large-scale features of the storm tracks in the reanalysis data. Quantitatively, the $\mathrm{MMM} \mathrm{EKE}_{<2 \mathrm{~d}}, \mathrm{EKE}_{2-8 \mathrm{~d}}$, and $\mathrm{EKE}_{<8 \mathrm{~d}}$ are found to account for about $17 \%, 40 \%$, and $57 \%$ of the MMM EKE $<\mathrm{yr}$ respectively, and these percentage contributions are similar to those in ERAInterim and JRA-55 (Fig. 3d). The large percentage of $\mathrm{EKE}_{<\mathrm{yr}}$ accounted by $\mathrm{EKE}_{<8 \mathrm{~d}}$ explains why wind fluctuations on a relatively narrow time-scale range of $6 \mathrm{~h}-8$ days, when combined with the climatological mean wind, make a disproportionately large contribution to the strength of the mean stress via the nonlinear stress law (Fig. 3b).

\section{b. Seasonal cycle}

In this section we examine the effect of wind fluctuations on the seasonal cycle of SO wind stress in CMIP5 models. Despite considerable differences among the CMIP5 models in their simulated seasonal variations of zonal-mean winds and wind stresses, there are, again, a few common features (Fig. 5). In almost all 18 CMIP5 models, the maximum zonal-mean zonal wind shifts to its most equatorward position in austral summer (dashed red), whereas the zonal-mean zonal wind becomes weaker and broader in austral winter (dashed black). This behavior is consistent with the northward expansion of the SH westerly wind belt and decreased wind intensity in austral winter found by Lamy et al. (2010) and O'Kane et al. (2017). In austral winter, the enhanced SO meridional temperature gradients increase the available potential energy stored in the westerly winds (Gill 1982). This subsequently leads to stronger atmospheric eddy activity and eddy-induced meridional momentum transport, which modulates the strength and position of surface SO winds (Trenberth 1987; Lamy et al. 2010). Larger EKE associated with enhanced eddy activities in austral winter can be found in Fig. 6.

In most models, the peak zonal-mean zonal wind stresses in austral spring and autumn are much larger than those in summer and winter (Fig. 5). These features are also clearly seen in the MMM plot (Fig. 5s) and are consistent with results from both reanalysis products (Figs. 5t,u). Interestingly, although the magnitude of the peak MMM zonal-mean wind in austral summer is significantly greater than that in austral winter (by $\sim 21 \%$; red vs black dashed in Fig. 5s), the peak MMM zonalmean wind stress in austral summer is almost of the same strength as that in austral winter (red vs black solid). In the two reanalysis products, the magnitude of the peak zonal-mean wind in austral summer is greater than that in austral winter, while the peak zonal-mean wind stress in austral summer is smaller than that in austral winter (Figs. 5t,u; see also Lin et al. 2018). This paradox can be explained by the pronounced seasonal cycle of the intensity of wind fluctuations in the SO. In all 18 CMIP5 models and both reanalysis products, the magnitude of wind fluctuations is the largest in austral winter and smallest in austral summer (black and red dashed in Fig. 6), and EKE is much greater than MKE in austral winter at all latitudes in the SO (black dashed vs solid). Therefore, stronger wind variability in austral winter significantly enhances the winter-mean zonal wind stress via the nonlinear stress law, which brings its peak strength to the same level as that in austral summer, even though the peak zonal-mean wind in austral winter is considerably weaker than that in austral summer.

Seasonal variability of the peak values of 19792005 monthly mean and zonal-mean $\tau_{>6 \mathrm{hr}}$ in the SO is dominated by a semiannual cycle in all 18 CMIP5 models, despite the large intermodel spread (Fig. 7a). The pattern of MMM wind stress (black solid), similar to those from JRA-55 (blue solid) and ERA-Interim (red solid), is characterized by maximum values in austral autumn (April) and spring (October) and minimum values in austral winter (June/July) and summer (December). However, the magnitude of MMM wind stress is somewhat smaller than those from JRA-55 and ERAInterim. To understand where this semiannual cycle of peak zonal-mean $\tau_{>6 \mathrm{hr}}$ comes from, we examined the seasonal variability of the peak values of monthly mean and zonal-mean MKE and EKE at the latitude of peak monthly mean and zonal-mean $\tau_{>6 \mathrm{hr}}$ (Figs. $7 \mathrm{~b}, \mathrm{c}$ ). It becomes clear that the semiannual cycle of peak zonalmean $\tau_{>6 \mathrm{hr}}$ in the SO is associated with the semiannual 

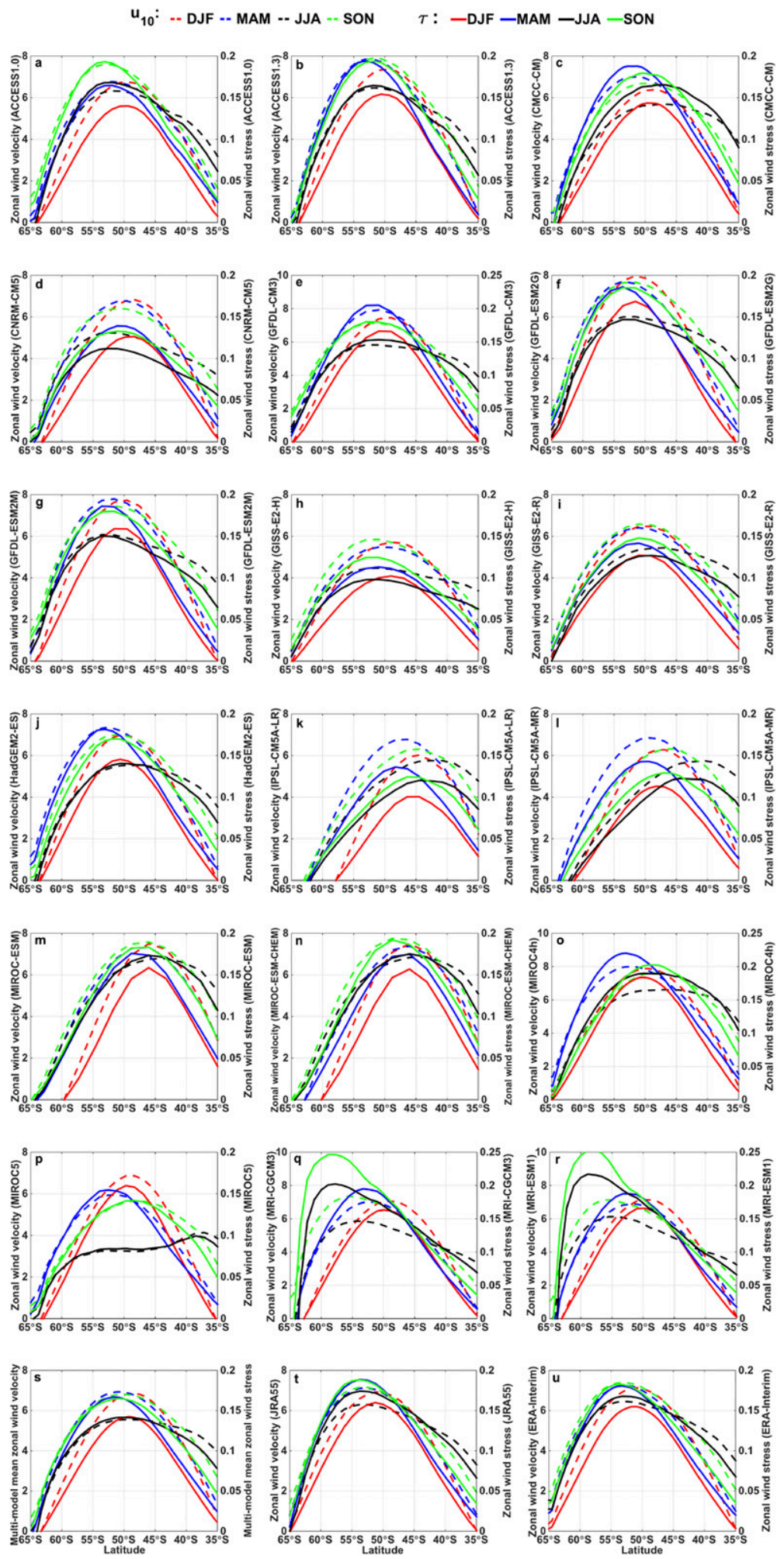

FIG. 5. The 1979-2005 seasonal-mean and zonal-mean zonal wind velocities (dashed; $\mathrm{m} \mathrm{s}^{-1}$ ) and zonal wind stresses (solid; $\mathrm{N} \mathrm{m}^{-2}$ ) from (a)-(r) the 18 CMIP5 models, (s) their multimodel mean, (t) JRA-55, and (u) ERA-Interim. 

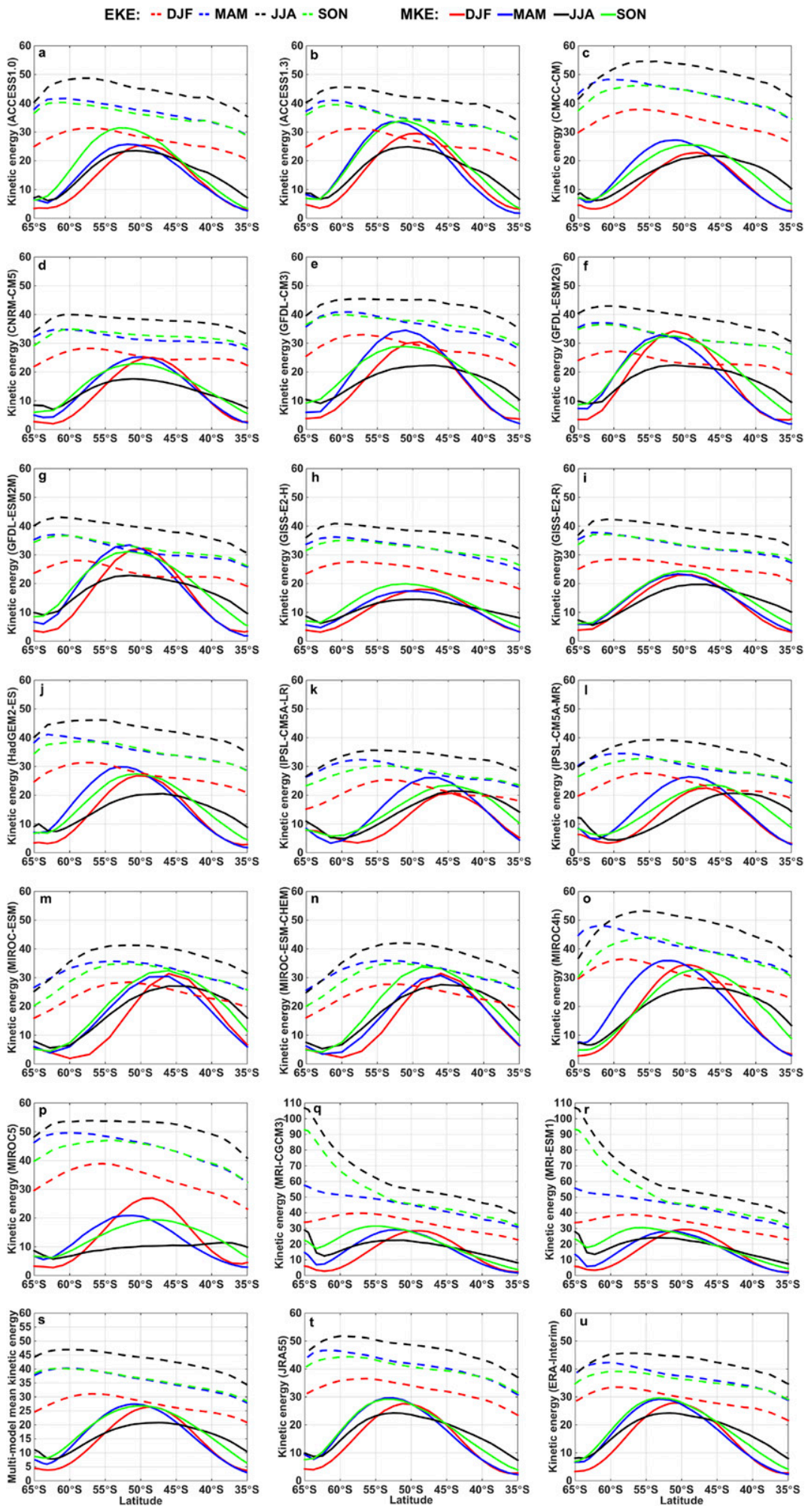

FIG. 6. The 1979-2005 seasonal-mean and zonal-mean mean kinetic energy (solid; $\mathrm{m}^{2} \mathrm{~s}^{-2}$ ) and eddy kinetic energy (dashed; $\mathrm{m}^{2} \mathrm{~s}^{-2}$ ) from (a)-(r) the 18 CMIP5 models, (s) their multimodel mean, (t) JRA-55, and (u) ERA-Interim. 

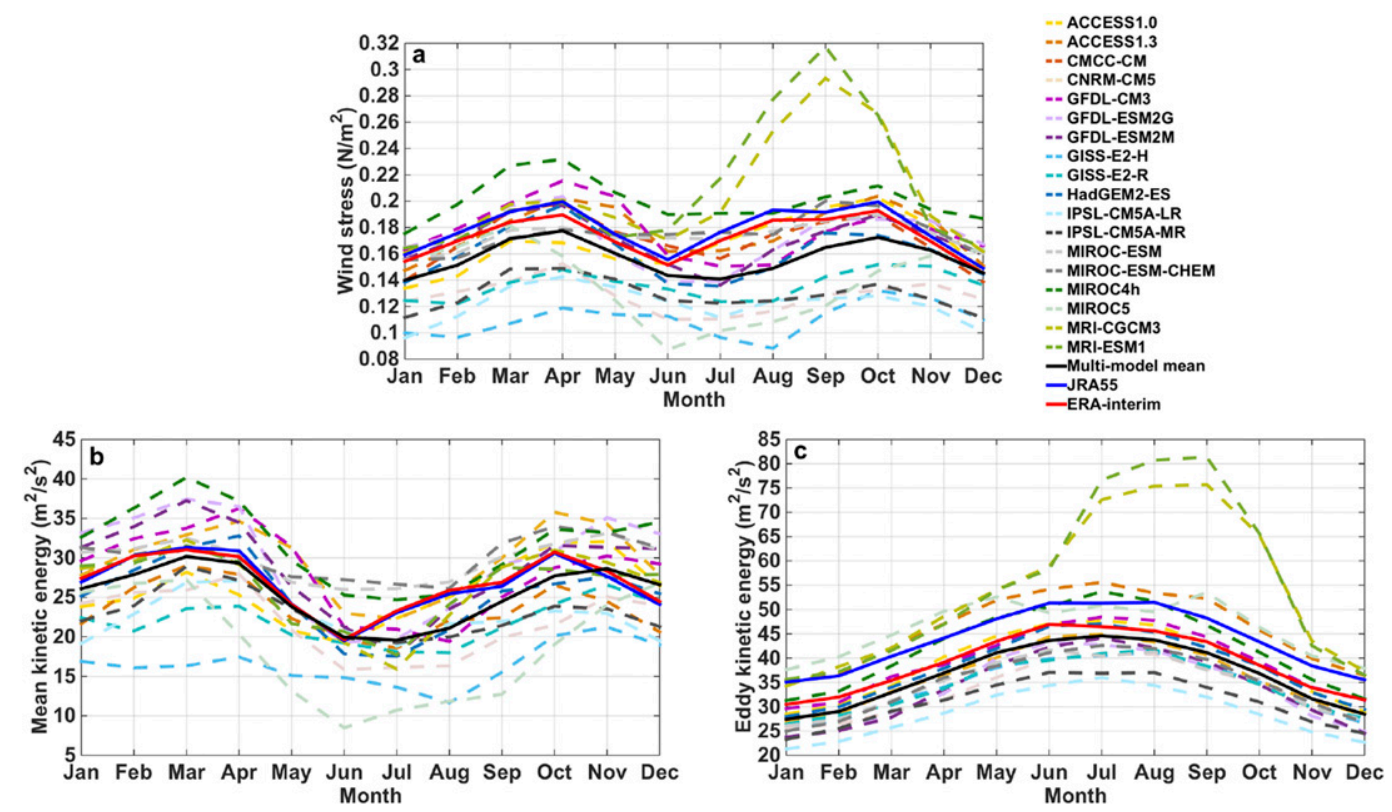

FIG. 7. Seasonal variability of (a) the peak values of 1979-2005 monthly mean and zonal-mean zonal wind stress $\tau_{>6 \mathrm{hr}}\left(\mathrm{N} \mathrm{m}^{-2}\right)$, (b) mean kinetic energy $\left(\mathrm{m}^{2} \mathrm{~s}^{-2}\right)$, and (c) eddy kinetic energy $\left(\mathrm{m}^{2} \mathrm{~s}^{-2}\right)$ over the SO $\left(35^{\circ}-65^{\circ} \mathrm{S}\right)$ from the 18 CMIP5 models (dashed), their multimodel mean (solid black), JRA-55 (solid blue), and ERA-Interim (solid red).

cycle of the strength of the mean wind. This semiannual oscillation of SO zonal-mean winds is a well-known phenomenon and is caused by the variability of temperature gradients in the middle troposphere (van Loon 1967). In contrast, the peak zonal-mean EKE in 17 out of 18 CMIP5 models as well as in both reanalysis products shows a pronounced annual cycle with its maximum in austral winter and minimum in austral summer (Fig. 7c). Figure 7 also shows the extremely large zonal-mean wind stress and EKE in MRICGCM3 and MRI-ESM1 in months from July to October. The unrealistically large EKE in MRI-CGCM3 and MRI-ESM1 in austral winter and spring (see also in Figs. 6q and 6r) contributes to the large and heavily southward skewed wind stress in these two seasons (see also in Figs. 5q and 5r).

\section{c. Trend}

Wind stresses and kinetic energy at the position of peak annual-mean and zonal-mean $\tau_{>6 \mathrm{hr}}$ are used for trend calculation. Only 11 out of the 18 CMIP5 models show significant wind stress $\left(\tau_{>6 \mathrm{hr}}\right)$ trends at $<5 \%$ level by a two-sided $t$ test over the period of 1960-2005 (Table 3). The trends calculated from wind stresses (tauu) directly output by CMIP5 models are also only significant in the same 11 models. Peak annual-mean and zonal-mean SO wind stresses $\tau_{>6 \mathrm{hr}}$ (black) and $\tau_{>\mathrm{yr}}$ (gray) and kinetic energy $\mathrm{MKE}_{<\mathrm{yr}}($ yellow-green) and
$\mathrm{EKE}_{<\mathrm{yr}}$ (green) from 1960 to 2005 in these 11 CMIP5 models are shown in Fig. 8 and their trends are given in Table 3. Not all these 11 models have significant trends in $\tau_{>\mathrm{yr}}$ over this period; the trend of $\tau_{>\mathrm{yr}}$ is not significant in GFDL-ESM2M. In the 10 models where both the trends of $\tau_{>6 \mathrm{hr}}$ and $\tau_{>\mathrm{yr}}$ are significant, the trends of $\tau_{>6 \mathrm{hr}}$ are, on average, over $50 \%$ greater than those of $\tau_{>\mathrm{yr}}$, demonstrating the amplification effect of wind fluctuations on the calculated wind stress trend (Table 3). Furthermore, this amplification effect exists regardless of whether there is trend in the intensity of wind fluctuations. Due to the nonlinearity in the stress calculation, differences in the mean winds influence the effects that wind fluctuations have on the mean stress and its trend. In seven CMIP5 models, the peak annual-mean and zonalmean SO wind stress $\left(\tau_{>6 \mathrm{hr}}\right)$ exhibit a significant poleward shift of about $1^{\circ}-2^{\circ}$ over the period of $1960-2005$ (not shown).

Consistent with the significant trends of $\tau_{>\mathrm{yr}}$, the trends of $\mathrm{MKE}_{<\mathrm{yr}}$ are also significant in the same 10 CMIP5 models, while the trend of $\mathrm{EKE}_{<\mathrm{yr}}$ is not significant in any of these 10 models (Table 3). Therefore, the wind stress trends in these 10 models are due to the strengthening of the mean winds, not the increase in storm activities. This is similar to the result derived from ERA-Interim data over 1979-2016; that is, the strengthening SO wind stress in ERA-Interim is caused by the increasing strength of the mean westerly wind 
TABLE 3. Significant trends of SO wind stresses $\left(10^{-4} \mathrm{~N} \mathrm{~m}^{-2} \mathrm{yr}^{-1}\right)$ in 11 CMIP5 models over the period of 1960-2005 calculated from model output wind stress (tauu) and $\tau_{>6 \mathrm{hr}}$, as well as trends of $\tau_{>\mathrm{yr}}\left(10^{-4} \mathrm{~N} \mathrm{~m}^{-2} \mathrm{yr}^{-1}\right)$ and kinetic energy $\left(10^{-2} \mathrm{~m}^{2} \mathrm{~s}^{-2} \mathrm{yr}^{-1}\right)$ in these 11 models. Trends not significant at the $<5 \%$ level by a two-sided $t$ test are marked with a slash (/).

\begin{tabular}{|c|c|c|c|c|c|c|c|c|}
\hline Model name & tauu & $\tau_{>6 \mathrm{hr}}$ & $\tau_{>\mathrm{yr}}$ & $\mathrm{MKE}_{<\mathrm{yr}}$ & $\mathrm{EKE}_{<\mathrm{yr}}$ & $\mathrm{EKE}_{<8 \mathrm{~d}}$ & $\mathrm{EKE}_{<2 \mathrm{~d}}$ & $\mathrm{EKE}_{2-8 \mathrm{~d}}$ \\
\hline ACCESS1.0 & 3.2 & 3.1 & 2.1 & 6.5 & l & 1.6 & 1.2 & l \\
\hline ACCESS1.3 & 2.9 & 2.8 & 2.1 & 6.9 & 1 & 1 & 0.8 & 1 \\
\hline CMCC-CM & 3.7 & 3.9 & 2.2 & 6.9 & l & 1.8 & 1 & 1.2 \\
\hline GFDL CM3 & 2.9 & 3.8 & 2.6 & 8.3 & l & I & 1 & 1 \\
\hline GFDL-ESM2G & 3.3 & 3.8 & 2.2 & 7.2 & 1 & 1.9 & 1 & 1.3 \\
\hline GFDL-ESM2M & 2.4 & 2.8 & 1 & 1 & 2.8 & 2.1 & 1.0 & 1.1 \\
\hline GISS-E2-H & 2.7 & 3.2 & 1.9 & 6.5 & 1 & l & 1.0 & l \\
\hline GISS-E2-R & 3.4 & 2.9 & 1.7 & 5.8 & l & 1.9 & 0.9 & 1.0 \\
\hline IPSL-CM5A-LR & 3.7 & 2.9 & 2.1 & 7.2 & l & l & 0.6 & / \\
\hline MIROC-ESM-CHEM & 2.3 & 2.4 & 1.8 & 5.7 & l & l & 1 & l \\
\hline MRI-ESM1 & 3.1 & 4.6 & 2.1 & 7.1 & l & l & l & l \\
\hline
\end{tabular}

(Lin et al. 2018). In contrast, the trend of $\mathrm{EKE}_{<\mathrm{yr}}$ over the period of 1960-2005 is significant only in GFDLESM2M. However, the trends of $\tau_{>\mathrm{yr}}$ and $\mathrm{MKE}_{<\mathrm{yr}}$ are not significant in this model (Table 3). Therefore, the significant trend of $\tau_{>6 \mathrm{hr}}$ in GFDL-ESM2M is caused by increased wind fluctuations, especially those on time scales less than 8 days (significant trend of $\mathrm{EKE}_{<8 \mathrm{~d}}$ in Table 3), rather than the strengthening of the mean wind. The positive trends of $\mathrm{EKE}_{<8 \mathrm{~d}}, \mathrm{EKE}_{<2 \mathrm{~d}}$, and $\mathrm{EKE}_{2-8 \mathrm{~d}}$ are significant in five, six, and four models, respectively.

Based on the idealized model results of Munday and Zhai (2017), we expect the different contributions of wind fluctuations to wind stress trends in GFDLESM2M and other models to lead to considerable differences in the model-simulated SO overturning circulation and water mass formation in response to forcing changes. For example, Downes and Hogg (2013) found different strengths and changes of SO meridional overturning circulation in ACCESS1.0, ACCESS1.3, and GFDL-ESM2M, all three of which share the same ocean model but have different atmosphere, land, and sea ice components. Although the eddy-induced overturning circulation in GFDL-ESM2M is weaker during the historical period compared to ACCESS1.0 and ACCESS1.3, the increase in the strength of the eddy-driven overturning in response to the RCP8.5 forcing is larger in GFDL-ESM2M (Figs. 8 and 9 in Downes and Hogg 2013).

It is instructive to further examine the stress trends in different seasons in the 11 models with significant wind stress trends over the period of 1960-2005 to distinguish the contributions from different seasons. Note that the other seven CMIP5 models with no significant trend over this period show either no significant trend in any season or only a weak trend in DJF. Table 4 shows that no CMIP5 models have significant trends in $\tau_{>6 \mathrm{hr}}$ in all four seasons over this period. The wind stress trends are found to be significant in austral summer (DJF) in 9 out of these 11 CMIP5 models, whereas in other seasons they are significant only in a few models. Lin et al. (2018) also found that during 1979-2016 the trend of SO wind stress in ERA-Interim is significant only in austral summer and autumn. The strengthening trends are largest in austral summer in both reanalysis data and CMIP5 models over the period of 1979-2010 have also been reported by Swart and Fyfe (2012). Previous radiosonde and modeling studies show that the particularly large positive trend of SH circumpolar westerly wind during austral summer is driven primarily by the large tropospheric response to stratospheric ozone depletion in this season (e.g., Thompson and Solomon 2002; Arblaster and Meehl 2006; Son et al. 2010; Thompson et al. 2011).

\section{Conclusions and discussion}

The SH surface westerly wind stress, a major driver for SO circulation and water mass transformation, is predicted to increase in the future. The recent modeling study by Munday and Zhai (2017) shows that the sensitivity of SO circulation to wind stress changes depends strongly on how these stress changes are brought about (i.e., by changes of the mean wind or wind variability). Although the enhancement of wind stress due to the inclusion of wind fluctuations is consistent across reanalysis products, the diagnosis of trends is not consistent (Lin et al. 2018), which may have important implications not only for SO circulation but also global ocean heat and carbon uptake. CMIP5 models are widely used to simulate historical and predict future changes of the SH westerly winds, SO circulation, and water mass properties. However, the role of wind fluctuations in determining the strength of SO wind stress in CMIP5 models has not been quantified before. In this 

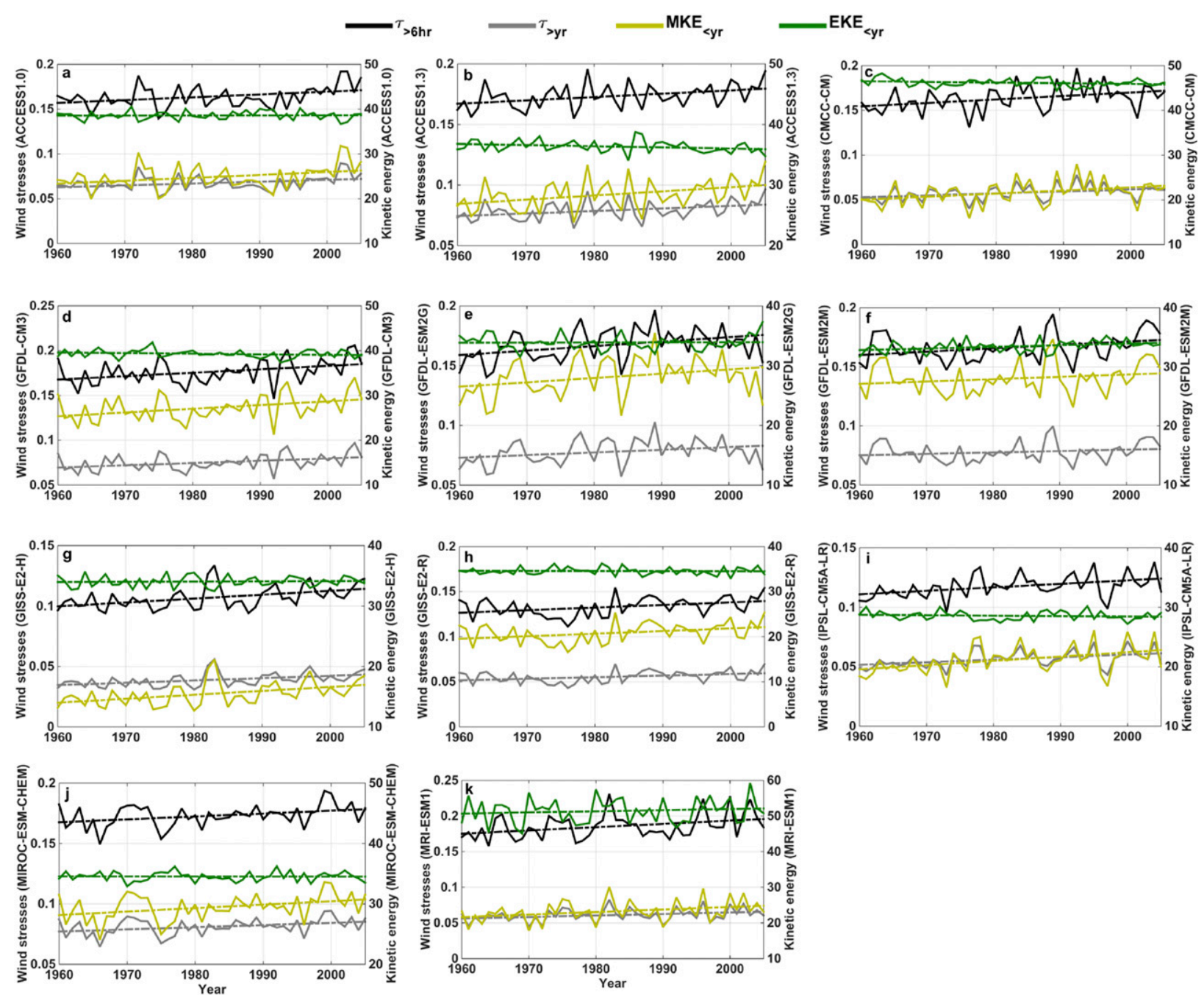

FIG. 8. Peak annual-mean and zonal-mean SO wind stresses $\tau_{>6 \mathrm{hr}}$ (black) and $\tau_{>\mathrm{yr}}$ (gray; $\mathrm{N} \mathrm{m}^{-2}$ ) and kinetic energy MKE $<$ yr $($ yellowgreen) and $\mathrm{EKE}_{<\mathrm{yr}}\left(\right.$ green; $\mathrm{m}^{2} \mathrm{~s}^{-2}$ ) at the position of peak annual-mean and zonal-mean $\tau_{>6 \mathrm{hr}}$ from 1960 to 2005 in the 11 CMIP5 models. The dash-dotted lines represent corresponding trends. Trends of $\tau_{>6 \mathrm{hr}}$ are significant in all 11 models, trends of $\tau_{>\mathrm{yr}}$ and MKE $\mathrm{Cyr}_{\mathrm{yr}}$ are significant in all 11 models except for GFDL-ESM2M, and the trend of EKE $<$ yr is only significant in GFDL-ESM2M (see Table 3).

study we have investigated the effects of wind fluctuations on the mean, seasonal cycle, and trend of SO wind stress in 18 CMIP5 models and compared them with results from two reanalysis products. Despite considerable intermodel spread, a few conclusions appear to be robust and are applicable to most, if not all, of the 18 CMIP5 models:

- Wind fluctuations strongly enhance the strength of the mean wind stress in the SO. This is expected given the large wind variability in this storm-track region and the nonlinear dependence of surface wind stress on surface wind velocity. Including wind fluctuations in the stress calculation is found to increase the magnitude of the peak MMM zonal-mean wind stress by about $145 \%$, with over $54 \%$ of the increase being contributed by wind fluctuations on time scales of 6 h-8 days.

- There is a pronounced seasonal cycle in the intensity of wind fluctuations in the SO, being lowest in austral summer and highest in austral winter. Stronger wind fluctuations bring the peak strength of the zonalmean wind stress in austral winter to the same level as that in austral summer, even though the magnitude of the zonal-mean wind in austral winter is considerably smaller than that in austral summer. The seasonal variability of the peak zonal-mean zonal wind and zonal wind stress is dominated by a semiannual cycle, characterized by maxima in austral autumn and spring and minima in austral winter and summer. 
TABLE 4. Seasonal trends of SO wind stress $\left(10^{-4} \mathrm{~N} \mathrm{~m}^{-2} \mathrm{yr}^{-1}\right)$ over the period of 1960-2005 from 11 CMIP5 models in Table 3. Trends not significant at the $<5 \%$ level by a two-sided $t$ test are marked with a slash (/). DJF, MAM, JJA, and SON represent austral summer, autumn, winter, and spring, respectively.

\begin{tabular}{lcccc}
\hline \hline \multicolumn{1}{c}{ Model name } & DJF & MAM & JJA & SON \\
\hline ACCESS1.0 & 5.0 & $/$ & $/$ & $/$ \\
ACCESS1.3 & $/$ & $/$ & $/$ & 3.5 \\
CMCC-CM & $/$ & $/$ & 8.0 & 7.0 \\
GFDL CM3 & 5.6 & 3.5 & $/$ & 5.7 \\
GFDL-ESM2G & 4.9 & 5.5 & $/$ & $/$ \\
GFDL-ESM2M & 4.4 & $/$ & $/$ & $/$ \\
GISS-E2-H & 5.2 & $/$ & $/$ & $/$ \\
GISS-E2-R & 2.6 & 5.0 & $/$ & $/$ \\
IPSL-CM5A-LR & 3.0 & 3.4 & $/$ & $/$ \\
MIROC-ESM-CHEM & 3.1 & $/$ & $/$ & $/$ \\
MRI-ESM1 & 7.8 & $/$ & $/$ & $/$ \\
\hline
\end{tabular}

- The trends of SO $\tau_{>6 \text { hr }}$ over the period of 1960-2005 are significant in 11 out of the 18 CMIP5 models. Among the 11 models, the trend of atmospheric EKE is significant in GFDL-ESM2M but not in the other 10 models, while the trend of $\tau_{>\mathrm{yr}}$ is significant in the other 10 models but not in GFDL-ESM2M. The significant stress trend in GFDLESM2M is due to the significant increase in the intensity of wind fluctuations, while the trends in the other 10 models are due to the significant strengthening of the mean westerly wind. Due to the amplification effect of wind fluctuations, the trend of $\tau_{>6 \mathrm{hr}}$ is, on average, over $50 \%$ larger than the trend of $\tau_{>\mathrm{yr}}$. Furthermore, the trends of $\tau_{>6 \mathrm{hr}}$ are found to be significant in austral summer in 9 CMIP5 models, whereas in other seasons they are significant in many fewer models.

Perhaps not surprisingly, we have found a large spread in the simulated trends of SO wind and wind stress among the 18 CMIP5 models: 11 models with significant trends in wind stress, 10 with significant trends in mean wind, and 1 with significant trend in wind fluctuations. These large trend discrepancies may have contributed to the differences seen in the simulated historical changes of SO circulation and property distributions in CMIP5 models (e.g., Wang et al. 2011; Meijers et al. 2012; Downes and Hogg 2013; Sallée et al. 2013a,b; Wang 2013; Meijers 2014; Russell et al. 2018).

Two dynamical concepts ("eddy saturation" and "eddy compensation") have been proposed in studies investigating the response of SO circulation to wind stress changes using eddy-resolving or eddy-permitting models in recent decades. Eddy saturation and eddy compensation refer to reduced sensitivity of Antarctic Circumpolar Current (ACC) transport and SO meridional overturning circulation to wind stress changes, respectively (Straub 1993; Viebahn and Eden 2010). In the eddy-saturation limit, the ACC transport is insensitive to the strengthened wind stress (Straub 1993; Hallberg and Gnanadesikan 2006; Munday et al. 2013). Differences in wind stress trends in CMIP5 models may not be crucial for modeled ACC transport as no significant relationship has been found between modeled ACC transport and the strength or position of SO wind stress (Wang et al. 2011; Meijers et al. 2012; Downes and Hogg 2013). Differences in the contributions of wind fluctuations to the stress trends among CMIP5 models, on the other hand, may lead to considerable differences in the simulated response of eddy-driven meridional overturning circulation as shown in Munday and Zhai (2017), thereby affecting the level of eddy compensation in the SO. The significant wind stress trend in GFDL-ESM2M is due to the increase in the intensity of wind fluctuations, while in ACCESS1.0 and ACCESS1.3 wind stress trends are due to the strengthening of the mean winds (Table 3). The increased storminess in GFDL-ESM2M could potentially enhance diabatic processes in the upper ocean and lead to a greater sensitivity of SO residual overturning circulation to wind stress changes in this model (Downes and Hogg 2013). Results from this study suggest that both the mean wind and wind fluctuations need to be better simulated in CMIP5 models in order to reduce the uncertainty in model-predicted SO response to forcing changes in the future.

Acknowledgments. This study is supported by the National Key R\&D Program of China (2016YFA0601804) and the Priority Academic Program Development of JiangSu Higher Education Institutions. XL is supported by the project (41906190) of National Natural Science Foundation of China, the Fundamental Research Funds for the Central Universities (2019B19014), and the China Postdoctoral Science Foundation (2019M661705). XZ acknowledges support by a Royal Society International Exchanges Award (IE131025). ZW is supported by the project (41876220) of National Natural Science Foundation of China and the Fundamental Research Funds for the Central Universities (2017B04814, 2017B20714). DRM is supported by the Natural Environment Research Council (ORCHESTRA, Grant NE/N018095/1).

\section{REFERENCES}

Arblaster, J. M., and G. A. Meehl, 2006: Contributions of external forcings to southern annular mode trends. J. Climate, 19, 28962905, https://doi.org/10.1175/JCLI3774.1.

Barnes, E. A., and L. Polvani, 2013: Response of the midlatitude jets, and of their variability, to increased greenhouse gases in the CMIP5 models. J. Climate, 26, 7117-7135, https://doi.org/ 10.1175/JCLI-D-12-00536.1.

Beljaars, A. C. M., 1995: The parametrization of surface fluxes in large-scale models under free convection. Quart. J. Roy. Meteor. Soc., 121, 255-270, https://doi.org/10.1002/qj.49712152203. 
Bracegirdle, T. J., and Coauthors, 2013: Assessment of surface winds over the Atlantic, Indian and Pacific Ocean sectors of the Southern Ocean in CMIP5 models: Historical bias, forcing response, and state dependence. J. Geophys. Res. Atmos., 118, 547-562, https://doi.org/10.1002/JGRD.50153.

Ceppi, P., Y.-T. Hwang, D. M. Frierson, and D. L. Hartmann, 2012: Southern Hemisphere jet latitude biases in CMIP5 models linked to shortwave cloud forcing. Geophys. Res. Lett., 39, L19708, https://doi.org/10.1029/2012GL053115.

Dee, D. P., and Coauthors, 2011: The ERA-Interim reanalysis: Configuration and performance of the data assimilation system. Quart. J. Roy. Meteor. Soc., 137, 553-597, https://doi.org/ 10.1002/qj.828.

Downes, S. M., and A. M. Hogg, 2013: Southern Ocean circulation and eddy compensation in CMIP5 models. J. Climate, 26, 7198-7220, https://doi.org/10.1175/JCLI-D-12-00504.1.

Fairall, C. W., E. F. Bradley, J. E. Hare, A. A. Grachev, and J. B. Edson, 2003: Bulk parameterization of air-sea fluxes: Updates and verification for the COARE algorithm. J. Climate, 16, 571-591, https:// doi.org/10.1175/1520-0442(2003)016<0571:BPOASF >2.0.CO;2.

Garratt, J. R., 1994: The Atmospheric Boundary Layer. Cambridge University Press, $316 \mathrm{pp}$.

Gent, P., 2016: Effects of Southern Hemisphere wind changes on the meridional overturning circulation in ocean models. Annu. Rev. Mar. Sci., 8, 79-94, https://doi.org/10.1146/annurev-marine-122414033929.

Gill, A. E., 1982: Atmosphere-Ocean Dynamics. Academic Press, 662 pp.

Gille, S. T., 2008: Decadal-scale temperature trends in the Southern Hemisphere ocean. J. Climate, 21, 4749-4765, https:// doi.org/10.1175/2008JCLI2131.1.

Hallberg, R., and A. Gnanadesikan, 2006: The role of eddies in determining the structure and response of the wind-driven Southern Hemisphere overturning: Results from the Modeling Eddies in the Southern Ocean (MESO) project. J. Phys. Oceanogr., 36, 2232-2252, https://doi.org/10.1175/JPO2980.1.

Harvey, B. J., L. C. Shaffrey, T. J. Woollings, G. Zappa, and K. I. Hodges, 2012: How large are projected 21st century storm track changes? Geophys. Res. Lett., 39, L18707, https://doi.org/ 10.1029/2012GL052873.

Hines, K. M., D. H. Bromwich, and G. J. Marshall, 2000: Artificial surface pressure trends in the NCEP-NCAR reanalysis over the Southern Ocean and Antarctica. J. Climate, 13, 3940-3952, https:// doi.org/10.1175/1520-0442(2000)013<3940:ASPTIT>2.0.CO;2.

Jones, J. M., and Coauthors, 2016: Assessing recent trends in highlatitude Southern Hemisphere surface climate. Nat. Climate Change, 6, 917-926, https://doi.org/10.1038/nclimate3103.

Kistler, R., and Coauthors, 2001: The NCEP-NCAR 50-Year Reanalysis: Monthly means CD-ROM and documentation. Bull. Amer. Meteor. Soc., 82, 247-267, https://doi.org/10.1175/ 1520-0477(2001)082<0247:TNNYRM >2.3.CO;2.

Knutti, R., D. Masson, and A. Gettelman, 2013: Climate model genealogy: Generation CMIP5 and how we got there. Geophys. Res. Lett., 40, 1194-1199, https://doi.org/10.1002/grl.50256.

Kobayashi, S., and Coauthors, 2015: The JRA-55 Reanalysis: General specifications and basic characteristics. J. Meteor. Soc. Japan, 93, 5-48, https://doi.org/10.2151/jmsj.2015-001.

Lamy, F., R. Kilian, H. W. Arz, J. P. Francois, J. Kaiser, M. Prange, and T. Steinke, 2010: Holocene changes in the position and intensity of the southern westerly wind belt. Nat. Geosci., 3 , 695-699, https://doi.org/10.1038/ngeo959.

Langlais, C. E., S. R. Rintoul, and J. D. Zika, 2015: Sensitivity of Antarctic Circumpolar Current transport and eddy activity to wind patterns in the Southern Ocean. J. Phys. Oceanogr., 45, 1051-1067, https://doi.org/10.1175/JPO-D-14-0053.1.

Large, W. G., J. C. McWilliams, and S. C. Doney, 1994: Oceanic vertical mixing: A review and a model with a nonlocal boundary layer parameterization. Rev. Geophys., 32, 363-403, https://doi.org/10.1029/94RG01872.

Lee, T., D. E. Waliser, J.-L. F. Li, F. W. Landerer, and M. M. Gierach, 2013: Evaluation of CMIP3 and CMIP5 wind stress climatology using satellite measurements and atmospheric reanalysis products. J. Climate, 26, 5810-5826, https://doi.org/ 10.1175/JCLI-D-12-00591.1.

Le Quéré, C., and Coauthors, 2007: Saturation of the Southern Ocean $\mathrm{CO}_{2}$ sink due to recent climate change. Science, $\mathbf{3 1 6}$, 1735-1738, https://doi.org/10.1126/science.1136188.

Lin, X., X. Zhai, Z. Wang, and D. Munday, 2018: Mean, variability and trend of Southern Ocean wind stress: Role of wind fluctuations. J. Climate, 31, 3557-3573, https://doi.org/10.1175/ JCLI-D-17-0481.1.

Ma, Y., X. Zhou, D. Bi, Z. Sun, and A. C. Hirst, 2015: Improved air-sea flux algorithms in an ocean-atmosphere coupled model for simulation of global ocean SST and its tropical Pacific variability. Climate Dyn., 44, 1473-1485, https://doi.org/ 10.1007/s00382-014-2281-7.

Marshall, G. J., 2003: Trends in the southern annular mode from observations and reanalyses. J. Climate, 16, 4134-4143, https:// doi.org/10.1175/1520-0442(2003)016<4134:TITSAM >2.0.CO;2.

Marshall, J., and K. Speer, 2012: Closure of the meridional overturning circulation through Southern Ocean upwelling. Nat. Geosci., 5, 171-180, https://doi.org/10.1038/ngeo1391.

Meijers, A. J. S., 2014: The Southern Ocean in the Coupled Model Intercomparison Project phase 5. Philos. Trans. Roy. Soc., 372A, 20130296, https://doi.org/10.1098/rsta.2013.0296.

, E. Shuckburgh, N. Bruneau, J.-B. Sallée, T. J. Bracegirdle, and Z. Wang, 2012: Representation of the Antarctic Circumpolar Current in the CMIP5 climate models and future changes under warming scenarios. J. Geophys. Res., 117, C12008, https://doi.org/10.1029/2012JC008412.

Meredith, M. P., A. C. Naveira Garabato, A. M. Hogg, and R. Farneti, 2012: Sensitivity of the overturning circulation in the Southern Ocean to decadal changes in wind forcing. J. Climate, 25, 99-110, https://doi.org/10.1175/2011JCLI4204.1.

Munday, D. R., and X. Zhai, 2017: The impact of atmospheric storminess on the sensitivity of Southern Ocean circulation to wind stress changes. Ocean Modell., 115, 14-26, https:// doi.org/10.1016/j.ocemod.2017.05.005.

— , H. L. Johnson, and D. P. Marshall, 2013: Eddy saturation of equilibrated circumpolar currents. J. Phys. Oceanogr., 43, 507532, https://doi.org/10.1175/JPO-D-12-095.1.

O'Kane, T. J., D. P. Monselesan, and J. S. Risbey, 2017: A multiscale reexamination of the Pacific-South American pattern. Mon. Wea. Rev., 145, 379-402, https://doi.org/10.1175/MWR-D-16-0291.1.

Russell, J. L., and Coauthors, 2018: Metrics for the evaluation of the Southern Ocean in coupled climate models and Earth system models. J. Geophys. Res. Oceans, 123, 3120-3143, https://doi.org/10.1002/2017JC013461.

Sallée, J.-B., E. Shuckburgh, N. Bruneau, A. J. S. Meijers, T. J. Bracegirdle, and Z. Wang, 2013a: Assessment of Southern Ocean mixed layer depths in CMIP5 models: Historical bias and forcing response. J. Geophys. Res. Oceans, 118, 18451862, https://doi.org/10.1002/jgrc.20157.

$-,-,-\longrightarrow,-,-\longrightarrow$, and T. Roy, 2013b: Assessment of Southern Ocean water mass circulation and characteristics in CMIP5 models: Historical bias and forcing response. 
J. Geophys. Res. Oceans, 118, 1830-1844, https://doi.org/ 10.1002/jgrc. 20135.

Simpson, I. R., and L. M. Polvani, 2016: Revisiting the relationship between jet position, forced response, and annular mode variability in the southern midlatitudes. Geophys. Res. Lett., 43, 2896-2903, https://doi.org/10.1002/2016GL067989.

_, J. T. Bacmeister, I. Sandu, and M. J. Rodwell, 2018: Why do modeled and observed surface wind stress climatologies differ in the trade wind regions? J. Climate, 31, 491-513, https:// doi.org/10.1175/JCLI-D-17-0255.1.

Smith, S. D., 1988: Coefficients for sea surface wind stress, heat flux, and wind profiles as a function of wind speed and temperature. J. Geophys. Res., 93, 15 467-15 472, https://doi.org/10.1029/ JC093iC12p15467.

Son, S.-W., and Coauthors, 2010: Impact of stratospheric ozone on Southern Hemisphere circulation change: A multimodel assessment. J. Geophys. Res., 115, D00M07, https://doi.org/ 10.1029/2010JD014271.

Straub, D. N., 1993: On the transport and angular momentum balance of channel models of the Antarctic Circumpolar Current. J. Phys. Oceanogr., 23, 776-782, https://doi.org/ 10.1175/1520-0485(1993)023<0776:OTTAAM > 2.0.CO;2.

Swart, N. C., and J. C. Fyfe, 2012: Observed and simulated changes in the Southern Hemisphere surface westerly wind-stress. Geophys. Res. Lett., 39, L16711, https://doi.org/10.1029/ 2012 GL052810.

, — - N. Gillett, and G. J. Marshall, 2015: Comparing trends in the southern annular mode and surface westerly jet. J. Climate, 28, 8840-8859, https://doi.org/10.1175/JCLI-D-15-0334.1.

Thompson, D. W. J., and S. Solomon, 2002: Interpretation of recent Southern Hemisphere climate change. Science, 296, 895-899, https://doi.org/10.1126/science.1069270.

P. J. Kushner, M. H. England, K. M. Grise, and D. J. Karoly, 2011: Signatures of the Antarctic ozone hole in Southern Hemisphere surface climate change. Nat. Geosci., 4, 741-749, https://doi.org/10.1038/ngeo1296.

Trenberth, K. E., 1987: The role of eddies in maintaining the westerlies in the Southern Hemisphere winter. J. Atmos. Sci., 44, 1498-1508, https://doi.org/10.1175/1520-0469(1987)044<1498: TROEIM > 2.0.CO;2.

- 1991: Storm tracks in the Southern Hemisphere. J. Atmos. Sci., 48, 2159-2178, https://doi.org/10.1175/1520-0469(1991) 048<2159:STITSH $>2.0$.CO;2.

van Loon, H., 1967: The half-yearly oscillations in middle and high southern latitudes and the coreless winter. J. Atmos. Sci., 24,
472-486, https://doi.org/10.1175/1520-0469(1967)024<0472: THYOIM $>2.0 . \mathrm{CO} ; 2$.

Viebahn, J., and C. Eden, 2010: Towards the impact of eddies on the response of the Southern Ocean to climate change. Ocean Modell., 34, 150-165, https://doi.org/10.1016/j.ocemod.2010.05.005.

Wang, Z., 2013: On the response of Southern Hemisphere subpolar gyres to climate change in coupled climate models. J. Geophys. Res. Oceans, 118, 1070-1086, https://doi.org/10.1002/jgrc.20111.

— T. Kuhlbrodt, and M. P. Meredith, 2011: On the response of the Antarctic Circumpolar Current transport to climate change in coupled climate models. J. Geophys. Res., 116, C08011, https://doi.org/10.1029/2010JC006757.

—, X. Zhang, Z. Guan, B. Sun, X. Yang, and C. Liu, 2015: An atmospheric origin of the multi-decadal bipolar seesaw. Sci. Rep., 5, 8909, https://doi.org/10.1038/srep08909.

— Y. Wu, X. Lin, C. Liu, and Z. Xie, 2017: Impacts of openocean deep convection in the Weddell Sea on coastal and bottom water temperature. Climate Dyn., 48, 2967-2981, https://doi.org/10.1007/s00382-016-3244-y.

Wilcox, L. J., A. J. Charlton-Perez, and L. J. Gray, 2012: Trends in austral jet position in ensembles of high- and low-top CMIP5 models. J. Geophys. Res., 117, D13115, https://doi.org/10.1029/ 2012JD017597.

Wu, Y., X. Zhai, and Z. Wang, 2016: Impact of synoptic atmospheric forcing on the mean ocean circulation. J. Climate, 29, 5709-5724, https://doi.org/10.1175/JCLI-D-15-0819.1.

Yin, J. H., 2005: A consistent poleward shift of the storm tracks in simulations of 21st century climate. Geophys. Res. Lett., 32, L18701, https://doi.org/10.1029/2005GL023684.

Zhai, X., 2013: On the wind mechanical forcing of the ocean general circulation. J. Geophys. Res. Oceans, 118, 6561-6577, https://doi.org/10.1002/2013JC009086.

_ and C. Wunsch, 2013: On the variability of wind power input to the oceans with a focus on the subpolar North Atlantic. J. Climate, 26, 3892-3903, https://doi.org/10.1175/JCLI-D-12-00472.1.

- H. L. Johnson, D. P. Marshall, and C. Wunsch, 2012: On the wind power input to the ocean general circulation. J. Phys. Oceanogr., 42, 1357-1365, https://doi.org/10.1175/JPO-D-12-09.1.

Zika, J. D., and Coauthors, 2013a: Vertical eddy fluxes in the Southern Ocean. J. Phys. Oceanogr., 43, 941-955, https:// doi.org/10.1175/JPO-D-12-0178.1.

—, J. Le Sommer, C. O. Dufour, A. Naveira-Garabato, and A. Blaker, 2013b: Acceleration of the Antarctic Circumpolar Current by wind stress along the coast of Antarctica. J. Phys. Oceanogr., 43, 2772-2784, https://doi.org/10.1175/JPO-D-13-091.1. 